\title{
NUEVAS FORMAS DE TERRORISMO, NUEVOS INSTRUMENTOS PENALES: LA REPRESIÓN PENAL DE LA CAPTACIÓN Y ADIESTRAMIENTO TERRORISTA TRAS LA REFORMA DEL CÓDIGO PENAL DE LA LO 2/2015
}

\begin{abstract}
New forms of terrorism, new criminal instruments: the criminal repression of terrorist capture and training after the reform of the 2/2015 Penal Code
\end{abstract}

Alfonso Galán Muñoz.

Resumen: El presente trabajo analiza los cambios que la reforma realizada por la LO 2/2015 ha introducido en la legislación penal española antiterrorista. En concreto, se estudian como la irrupción del nuevo terrorismo yihadistas ha llevado al legislador español a tratar de atajar las conductas iniciales de adoctrinamiento, captación y entrenamiento terroristas, activas y pasivas, mediante la introducción de una serie de delitos que plantean problemas de coordinación con las figuras previamente existentes, y que además, en ocasiones, limitan de forma desproporcionada algunos derechos fundamentales, por lo que deberían ser sometidos a una profunda revisión.

Palabras claves: terrorismo, yihadismo, organización terrorista, terrorista individual, adoctrinamiento terrorista, captación terrorista, libertad de expresión, delito de sospecha.

Abstract: In this paper is analyzed the changes that the reform made by LO 2/2015 has introduced into Spanish antiterrorist criminal law. Specifically, is studied how the irruption of the new jihadist terrorism has led the Spanish legislator to try to avoid the initial behaviours of active and passive terrorist indoctrination, recruitment and training trough the introduction of a set of crimes, which generates problems of coordination with previously existing crimes, sometimes, limits disproportionately some fundamental rights and, therefore, should be subject to a deep review.

Keywords: terrorism, jihadism, terrorist organization, individual terrorist, terrorist indoctrination, terrorist recruitment, freedom of speech, crime of suspicion.

\section{La respuesta penal al terrorismo tradicional}

El fenómeno del terrorismo no es algo nuevo para el ordenamiento jurídicopenal español. Desgraciadamente y a diferencia de otros países de nuestro entorno España ha padecido durante años las consecuencias derivadas de la actuación dentro de su territorio de varias organizaciones terroristas que trataban de conseguir fines políticos diversos mediante el empleo de la violencia y la intimidación.

\footnotetext{
* Profesor Titular de Derecho Penal, Universidad Pablo de Olavide de Sevilla. Correo electrónico: agalmun@upo.es
}

Este artículo fue recibido el 22 de julio de 2016, siendo aprobada su publicación el 3 de octubre de 2016. 
Galán - Nuevas formas de terrorismo, nuevos instrumentos penales...

Secuestros, asesinatos, atentados con bombas con múltiples víctimas y afectados, desórdenes y daños públicos insertos en lo que se denominó "terrorismo de baja intensidad" han sido durante años parte de la realidad social española como consecuencia de la existencia de organizaciones terroristas como ETA o los, aparentemente hace ya tiempo olvidados, GRAPO.

No puede sorprender entonces que nuestro ordenamiento jurídico fuese, posiblemente junto al vigente en el Reino Unido, el que disponía de una mayor variedad de instrumentos penales tanto materiales como procesales específicamente destinados a luchar contra este fenómeno delictivo de entre todos los que existen en nuestro entorno jurídico-cultural. De hecho existe incluso en nuestro ordenamiento una previsión constitucional (la establecida en el art. $55.2 \mathrm{CE}$ ), que permite expresamente que dichos instrumentos puedan llegar a limitar los derechos y libertades fundamentales de los ciudadanos de forma mucho más severa que los que se creen contra cualquier otra clase de delincuencia, precisamente para poder luchar de la forma más eficaz posible contra su existencia y efectos lo que, de facto y a juicio de algunos autores, supone establecer una suerte de régimen de "estado de excepción" permanente con respecto al fenómeno terrorista. ${ }^{1}$

Ahora bien todos estos variados y excepcionales instrumentos se crearon para hacer frente a un terrorismo que podríamos calificar como clásico o tradicional. Un terrorismo que, pese a las evidentes diferencias que existen entre las organizaciones y fenómenos que podían ser incluidas en su concepto, presentaba una serie de notas comunes que fueron muy tenidas en cuenta e influyeron de forma notable en la concreta configuración de los instrumentos jurídico-penales creados para combatirlo.

Así y en primer lugar era un terrorismo realizado desde el seno de unas organizaciones complejas, dotadas de carácter permanente y estructuradas con distribución de funciones entre sus integrantes y con una fuerte jerarquización entre los mismos; características todas ellas que, entre otras cosas, les permitían acumular recursos de todo tipo (humanos, financieros, propagandísticos, etc...) para cometer los delitos que las caracterizaban como terroristas y que también hacían factible que pudiesen seguir ejecutándolos, aunque las autoridades

\footnotetext{
1 En este sentido, Cancio (2000: 88) señalaba que el comentado precepto daba anclaje constitucional a la consideración de la normativa procesal penal en materia terrorista como una regulación excepcional; mientras que González (2007: 246 y ss.) indica, acertadamente a nuestro modo de ver, que la amenaza y el temor continuados que plantea el terrorismo crea una situación que, si bien no da lugar a la aparición de los estados de excepción o de sitio de los que habla el art. 55.1. CE, sí que da lugar a una situación diferente de la pura normalidad. Una situación que se podría denominar como de tensión a la que precisamente trata de dar respuesta la creación de un conjunto de leyes penales especiales creadas frente al terrorismo. Llama la atención, en tal sentido, el hecho de que nueva reforma de los delitos terroristas se haya realizado mediante una Ley Orgánica, la 2/2015, de 30 de marzo independiente y diferente de la que ha supuesto la reforma general de muchos otros preceptos del Código Penal, tal como declara Cano (2015: 5).
} 
consiguiesen privar a su estructura de algunos de sus engranajes o integrantes individuales, por muy importantes que estos pudiesen ser (jefes, ideólogos, etc...) convirtiéndose así su mera existencia en una fuente productora de peligros mucho más graves y persistentes que los que generaba la delincuencia individual. ${ }^{2}$

Pese a todo no era este elemento estructural propio del terrorismo tradicional el que realmente distinguía y diferenciaba esta forma de criminalidad del resto de las manifestaciones delictivas contempladas en nuestra legislación. Evidentemente existen muchas otras actividades criminales tales como el tráfico de drogas o el de armas, la mafia o la trata de seres humanos, entre otras, que también se caracterizan por realizarse habitualmente desde o en el seno de organizaciones con las características anteriormente señaladas.

En realidad lo que diferenciaba a este fenómeno delictivo del resto de las manifestaciones de criminalidad organizada era el hecho de que los delitos terroristas se cometían con una finalidad de marcado carácter político. ${ }^{3}$ Primordialmente, con la de subvertir de una u otra forma el orden constitucional establecido mediante el empleo de medios violentos e intimidatorios y no a través de los cauces legal y democráticamente habilitados para poder cambiarlo. ${ }^{4}$

En efecto, los delitos terroristas se realizaban en ocasiones para conseguir la independencia de una parte del territorio nacional (p. ej. ETA, Exército Guerrilheiro do Povo Galego Ceive, IRA, etc...) y en otras, para imponer un modelo de Estado o de sistema económico diferente al existente (p. ej. GRAPO, Brigadas Rojas, etc... $)^{5}$ pero siempre tendían a obtener un fin político, que si bien

\footnotetext{
2 Así, por ejemplo, señala Sánchez (2008: 454 y 455) que, además de reducir la inhibición criminal, "...la suma de fuerzas, a planificación racional y la división eficaz del trabajo y la profesionalización de las organizaciones fundamentan un mayor peligro para los bienes jurídicos"; mientras que Núñez (2013: 80) destaca, específicamente en relación con los delitos terroristas que "...solo la organización tiene la suficiente potencialidad para cometer delitos de modo continuado, sembrar el terror social y transmitir un sentimiento de estabilidad, dotando de unidad y continuidad al plan diseñado y de coherencia al modo de conseguirlo"; siendo precisamente la existencia de la organización terrorista, según Gómez (2010: 31) la que añade a los delitos terroristas un triple elemento comunicativo, la permanencia del peligro latente, el anuncio de la reiteración delictiva y la capacidad de la organización para seguir atemorizando a la población.

${ }^{3}$ Así, señalaba Muñoz (2010: 923) en relación a la legislación anterior que el terrorismo no era sino “...una forma más de criminalidad organizada, aunque con finalidad politica (...) que la hace más peligrosas y dificil de controlar". De hecho, Cancio (2011: 645) indicó en tal sentido que el fenómeno de la criminalidad organizada se manifestaba en dos direcciones diferentes: una orientada a lucro económico (la criminalidad organizada común) y otro hacía la política, donde estarían incardinadas las organizaciones terroristas; postura muy cercana a la sostenida, entre otros, por Núñez (2013: 76 y ss.). De otro parecer, sin embargo, era Zúñiga (2009: 135 y ss.) quien considera que al ser el fin último y fundamental de la criminalidad organizada la búsqueda del beneficio económico ilícito, hay que distinguir la criminalidad organizada como tal y la terrorista.

${ }^{4}$ De hecho, y en tal sentido, señalaba Asúa (2002: 83) que, si bien la pretensión de alterar el orden constitucional no era reprochable, dado que no es estático ni inamovible, lo que sí lo es, es “...la pretensión de alterar mediante el terror los procedimientos de participación política y de propuesta de proyectos de transformación de la organización institucional o de distribución del poder".

${ }^{5}$ Es por ello, por lo que Cano (2015b: 905) afirma que el terrorismo tradicional era un terrorismo "de corte etno-nacionalista o social-revolucionario".
} 
Galán - Nuevas formas de terrorismo, nuevos instrumentos penales...

no tenía por qué ser ilegítimo en sí mismo, se pretendía alcanzar mediante la utilización de la coacción que suponía la amenaza o efectiva producción de resultados gravemente lesivos para los derechos más fundamentales de los ciudadanos (vida, salud, libertad, etc...).

Precisamente por ello este terrorismo también tenía un marcado carácter nacional, ya que por más que hayan existido supuestos en los que las distintas organizaciones terroristas afincadas en diferentes países han llegado a colaborar y se han brindado apoyo logístico entre sí, ello nunca ha determinado que hayan llegado a dar un sentido unitario e internacional a sus actividades.

Todos estos caracteres llevaron a que el ordenamiento jurídico-penal español respondiese frente a esta clase de terrorismo de corte tradicional primordialmente de dos formas diversas y acumuladas.

Por una parte procedió a intensificar de forma notable la respuesta punitiva establecida frente a las actuaciones que les eran propias. Por otra, realizó una notable ampliación y adelantamiento de las posibilidades de intervenir penalmente frente a las mismas.

Lo primero lo hizo tanto incrementando de forma significativa las penas aplicables a muchos delitos (asesinatos, secuestros, detenciones ilegales, etc...) por el mero hecho de que se hubiesen cometido desde el seno de organizaciones terroristas y con las finalidades que estas perseguían ${ }^{6}$ así como estableciendo un régimen de determinación y, sobre todo, de ejecución de las penas aplicables a los responsables de dichos delitos especial y mucho más severo y riguroso que el previsto para el resto de conductas delictivas. ${ }^{7}$

Lo segundo se realizó no solo castigando las tradicionales formas de participación intentada (proposición, provocación y conspiración) con respecto a los delitos terroristas, sino también contemplando como delitos autónomos y consumados la realización de otras muchas conductas que se cometían en el seno. En torno o simplemente para favorecer o ayudar a las peligrosas organizaciones terroristas, pero que estaban todavía muy alejadas del comienzo de la ejecución de atentados que las caracterizaban, como sucedió por ejemplo con las que

\footnotetext{
${ }^{6}$ De hecho, resulta reseñable que, en realidad, el que la comisión de delitos desde o en las organizaciones terroristas diese lugar a una agravación de las penas aplicables a quienes los realicen era algo común a todos los delitos realizados por organizaciones criminales en general, como puso de manifiesto, por ejemplo, Cancio (2011: 645). Así lo señalaba también, por ejemplo, Muñoz (2015: 791) quien afirmaba que dentro de los delitos de terrorismo, incluso tras la reforma de la LO $2 / 2015$, continúa contemplándose un tratamiento especialmente agravatorio para los delitos comunes; postura que comparte Cano (2015b: 913).

7 Así sucedió, por ejemplo, con la LO 7/2003, de 30 de junio, de medidas de reforma para el cumplimiento íntegro y efectivo de las penas, que supuso una importante endurecimiento del régimen de cumplimiento de penas por delitos terrorista, como señaló en su día, por ejemplo, López (2003: 11 y ss.).
} 
sancionaban los delitos de pertenencia a organización terrorista (art. 571 ACP), de colaboración con la misma (art. 576 ACP) o el de simple enaltecimiento o justificación del terrorismo (art. 578 ACP).

Los instrumentos y mecanismos de respuesta penal al terrorismo tradicional como se puede comprobar eran severos, amplios y variados y también, por qué no decirlo, bastante controvertidos.

Sin embargo, el terrorismo ha evolucionado o mutado en los últimos tiempos, sobre todo como consecuencia de la aparición del denominado terrorismo yibadista; un terrorismo que presenta una serie de peculiaridades que lo distinguen y diferencian claramente del que hemos calificado como terrorismo "tradicional" lo que ha llevado a que se cuestione seriamente si los instrumentos desarrollados para luchar contra esta forma más clásica podrían resultar también adecuados y efectivos para hacerlo contra esta nueva realidad criminal.

\section{Nuevas formas de terrorismo, nuevos instrumentos penales}

El denominado terrorismo yibadista no es en realidad un fenómeno tan novedoso o reciente como se pudiera pensar en un primer momento.

Es indudable que existe y ha generado víctimas en muchos países del mundo desde hace muchos años.' Sin embargo, fueron los atentados del 11 de septiembre de 2001 en Nueva York o los cometidos en Madrid en 2004 o en Londres en 2005 los que hicieron a las sociedades occidentales tomar conciencia de la magnitud y, sobre todo, de la cercanía del riesgo que su existencia representaba para sus ciudadanos. ${ }^{10}$

Nos encontramos por tanto ante una forma de terrorismo que no es nueva, pero también ante una que presenta una serie de notas diferenciales con respecto a la tradicional, que deben ser muy tenidas en cuenta a la hora de darle adecuada respuesta penal.

\footnotetext{
8 De "nuevo" y "viejo" terrorismo hablaba, por ejemplo, Cano (2009: 2 y ss.) destacando las diferencias entre uno y otro.

9 Sobre los orígenes y ataques por todo el mundo que realizaron los diferentes movimientos terroristas yihadistas contemporáneos antes del 11 de septiembre, entre los que se encuentra el parece que ya olvidado primer atentado contra el Word Trade Center de Nueva York de 1993, véase lo comentado, por ejemplo, por Fuente (2015: 54 y ss.).

10 Así, señala González (2007: 233 y ss.) que, de hecho, tras los atentados del 11 de septiembre, el terrorismo dejó de ser considerado como una cuestión puramente criminal, pasando de ser un simple "riesgo" para la seguridad nacional a alcanzar la máxima categoría de "amenaza para la misma", en "Nuevas amenazas a la seguridad nacional...". Larriba (2009: 1089), por su parte, consideraba que han sido precisamente dichos atentados los han obligado a que se realice un replanteamiento de los parámetros que configuran los conflictos terroristas al plantear uno de los mayores desafíos a las democracias modernas.
} 
Galán - Nuevas formas de terrorismo, nuevos instrumentos penales...

Así y en primer lugar el terrorismo yihadista responde a la supuesta existencia de una guerra asimétrica y global que sus integrantes y partidarios han emprendido contra los países que consideran contrarios o enemigos de su "pueblo" o comunidad religiosa y de los valores que los caracterizan. Es, por tanto, un terrorismo que no trata de subvertir el orden constitucional del concreto país al que golpea. En ocasiones ni tan siquiera pretende lograr una finalidad propiamente política referida al mismo, como la de doblegar la voluntad de su opinión pública o políticos para que desistan, por ejemplo de tomar parte en una determinada campaña militar, sino que trata, simple y llanamente, de ocasionar dolor y terror a los habitantes de dicho país y a los de su entorno, como represalia y venganza por los agravios o daños que supuestamente estos habían contribuido previamente a ocasionar a las personas o países con los que el terrorista se identifica por razones presuntamente religiosas, aunque ni siquiera los conozcan y se encuentren a miles de kilómetros de distancia de donde vive y atenta.

Es entonces un terrorismo que tiene ya en su código genético un marcado carácter supra o transnacional muy conectado con una visión completamente maniquea del mundo, que clasifica a todas las personas en amigos (fieles, a los que hay que proteger $y$, en su caso, vengar) y enemigos (infieles, a los que simplemente hay que exterminar); visión que se ha expandido rápidamente a lo largo y ancho del globo, gracias entre otras cosas, a la difusión en los modernos medios de información y comunicación (principalmente internet) de un discurso marcadamente adoctrinador y basado en una concepción completamente manipulada y tergiversada de las tendencias más radicales del Islam y que trata precisamente de fomentar y de avivar el odio hacia aquellos a los que califica como infieles o enemigos.

Es por tanto un terrorismo no estrictamente político, pero sí uno dotado de un fuerte fundamento y discurso ideológico-religioso que se ha demostrado como tremendamente atractivo para determinadas capas de las sociedades actuales. Especialmente, aunque no de forma exclusiva, para aquellas que se conforman por los grupos de jóvenes de origen humilde, escasa formación y que viven sin demasiadas esperanzas de un futuro mejor. En muchas ocasiones, en verdaderos guetos incluidos dentro de las grandes ciudades occidentales y reservados aparentemente para los de su etnia o religión; sujetos a los que se trasmite el tal vez simplista, pero también muy seductor mensaje de que en realidad todo lo que padecen no es por culpa suya o del injusto sistema social en que les ha tocado vivir, sino que es un producto intencionadamente impuesto por los enemigos de su "gente" y de su religión. Enemigos contra los que evidentemente tienen que luchar.

Precisamente este marcado carácter adoctrinador del terrorismo yihadista es el que puede llevar y, de hecho ha llevado, a que algunas personas individuales que no contaban con apoyo ni contacto alguno con ninguna organización terrorista (los conocidos como "lobos solitarios") hayan efectuado de forma autónoma y por su cuenta y riesgo ataques contra los "enemigos" de su pueblo o religión y en 
apoyo de la "guerra santa" que creen se está librando contra los mismos, incluso aunque ello les haya supuesto tener que sacrificar su propia vida para poder llegar a hacerlo algo que, indudablemente, plantea serios y evidentes problemas a los tradicionales instrumentos penales de lucha contra el terrorismo.

Así por ejemplo ¿realmente los especiales y variados instrumentos jurídicos creados para luchar contra las estructuras criminales complejas, permanentes y altamente jerarquizadas propias del terrorismo tradicional y los sujetos que las integran, respaldan o ayudan pueden ser utilizados para responder adecuada y eficazmente a esta nueva forma de terrorismo incluso individual? Y en el mismo sentido ila estrategia político-criminal empleada contra el terrorismo tradicional, claramente volcada a la prevención general negativa mediante la amenaza de penas, en ocasiones draconianas para la realización de las actividades que les eran propias, pueden tener alguna eficacia preventiva a la hora de hacer frente a unos sujetos que están dispuestos incluso a perder la vida para apoyar y respaldar las ideas por las que dicen luchar? ¿Cómo puede intimidar a un posible terrorista para que no cometa un delito la amenaza de una pena de larga duración cuando está dispuesto a morir para ejecutarlo? ${ }^{11}$

Ninguna de estas preguntas parecía encontrar una respuesta afirmativa y plenamente satisfactoria y esto es lo que llevó tanto a nuestro legislador, como a todos los de los países occidentales y muchos organismo supra e internacionales -entre los que destaca la UE-, a tratar de crear nuevos mecanismos e instrumentos jurídicos que sirvan para responder de una forma más adecuada al reto que esta nueva forma de terrorismo les viene a plantear.

Para ello y en primer lugar han decidido responder al marcado carácter supranacional de esta nueva amenaza terrorista incrementando tanto los recursos como los sistemas de cooperación policial y judicial internacional en materia penal, mediante la creación y ratificación de numerosos instrumentos normativos inter y supranacionales que tratan de dotar a los organismos responsables de la prevención y lucha contra el terrorismo de medios técnicos, logísticos y normativos adecuados y suficientes para que puedan colaborar de la forma más rápida y eficaz posible en dicha tarea. ${ }^{12}$

\footnotetext{
11 También cuestiona dicho pretendido efecto motivador Cano (2015a: 14).

12 Llama la atención en tal sentido, la imparable aprobación de instrumentos de cooperación policial y judicial desarrollados a lo largo de los años en la UE, precisamente como consecuencia y en muchos casos a resultas de la realización de dichos atentados. Sobre este proceso, véase, por ejemplo, lo comentado por Fernández (2014: 338); Aixala (2015: 51) quien diferencia dos etapas distintas. Una primera que iría desde el atentado del 11 de septiembre en Nueva York hasta el del 11 de marzo en Madrid, donde, a su modo de ver, se adoptó un impulso primordialmente político a las medidas de cooperación judicial y policial en la UE, y otro que comenzaría con este último atentado, en el que se produjo un desarrollo mucho más técnico y, a su modo ver, también eficaz. En relación con esta evolución y, en especial con los cada vez más variados y utilizados mecanismos supranacionales de intercambio de información, véase, por ejemplo, Galán (2014: 3 y ss.), entre otros.
} 
Galán - Nuevas formas de terrorismo, nuevos instrumentos penales...

Por otra parte también se ha procedido a incrementar el número de posibles finalidades cuya persecución convertirá un delito en terrorista para permitir así que estas figuras no dejen escapar del excepcional régimen previsto para su investigación, persecución y castigo a ninguno de los que se comenten para respaldar los objetivos buscados por esta nueva forma de terrorismo siendo precisamente una de las más destacadas y controvertidas novedades introducidas en el Código Penal español por la reciente reforma realizada sobre el mismo por la LO 2/2015, aquella que ha venido a añadir a las tradicionales finalidades delimitadoras de las actividades terroristas (las de subvertir el orden constitucional o alterar gravemente la paz pública), ${ }^{13}$ otras como las de provocar terror en todo o en parte de la población, obligar a los poderes públicos a realizar u omitir actos que no tengan por qué hacer o dejar de hacer o, simplemente, la de alterar el funcionamiento de las instituciones estatales o de organizaciones internacionales; finalidades todas ellas que si bien puede ser que sirvan para perseguir y castigar anticipada y severamente las muy variadas actuaciones que pueden realizar estos nuevos terroristas, lo harán indudablemente a costas de ampliar y desdibujar hasta tal punto la tradicional delimitación del terrorismo que permitirán llegar a tenerse como tales a actuaciones que nada tienen que ver con dicho fenómeno lo que, sin duda, planteará enormes y difícilmente resolubles problemas de proporcionalidad y constitucionalidad. ${ }^{14}$

Otra medida claramente tendente a extender el posible campo de actuación de los excepcionales instrumentos jurídicos de lucha antiterrorista a las nuevas manifestaciones de las que venimos hablando ha consistido en permitir que el uso de tales instrumentos no queden ya exclusivamente limitados a las actividades

\footnotetext{
13 Respecto a dichas finalidades y su significado y papel véase, por ejemplo, lo comentado por Núñez (2013: 119 y ss.) o Gómez (2010: 45 y ss.), entre otros.

${ }^{14}$ Esta adicción que encuentra su origen en el art. 1.1. de la Decisión Marco 2002/475/JAI, de 13 de junio, que delimita de forma tan amplia y difusa los fines que darán lugar a que la apreciación de delitos terroristas, que podría llevar a que se pudiesen considerar también como tales conductas como, por ejemplo, las lesiones graves que se realicen con finalidad de atemorizar a una parte de la población (p. ej. homosexuales, emigrantes, etc...) o los incendios o daños que se puedan realizar durante una manifestación con la intención de interferir en el funcionamiento de una cámara parlamentaria; conductas éstas que, si bien resultan graves y pueden y deben ser penalmente perseguidas, no parece que hayan de mezclarse ni asimilarse a las verdaderamente terroristas, si no se quiere desdibujar los contornos que realmente diferencian y hacen más grave a esta forma de criminalidad frente a otras. En tal sentido, ya se manifestaba, por ejemplo, Núñez (2013: 79) quien consideraba que la ampliación de fines incluida en el Decisión Marco permitiría considerar como terrorista actuaciones que en modo alguno pretenderían atemorizar a la sociedad, con lo que se desdotaría al terrorismo de su tradicional elemento definidor; lo que se corresponde con lo más recientemente manifestado por Muñoz (2015: 790), quien ha señalado que la ampliación de posibles finalidades terroristas realizada por la LO 2/2015, puede llevar a que se incluyan en el concepto de terrorismo a numerosos movimientos sociales de protesta, incluso cometidos individualmente. Sin embargo y en claro contraste con lo anterior, otros autores, como Cano (2015b: 917) critican la inclusión de los comentados nuevos fines, precisamente por considerarla como innecesaria al resultar perfectamente subsumibles, a su modo de ver, en los que tradicionalmente han delimitado el terrorismo, esto es la de subvertir el orden constitucional y alterar la paz pública.
} 
desarrolladas por o en torno a organizaciones terroristas. Para conseguirlo en un primer momento se creó la controvertida figura del terrorista individual (art. 577 ACP), ${ }^{15}$ abriéndose posteriormente la utilización de los referidos instrumentos jurídicos especiales a los denominados grupos terroristas, concepto este mucho más amplio que el de organización y por ello se entendía que era más adecuado para luchar frente a las células autónomas propias del moderno terrorismo, ${ }^{16}$ llegándose finalmente y tras la entrada en vigor del nuevo art. 573 CP introducido por la LO 2/2015, a desdotar con carácter general a los delitos terroristas de la tradicional exigencia de la concurrencia en su realización del requisito estructural referido a su conexión con alguna de las citadas organizaciones o grupos lo que, de manera evidente, determinará que todo el peso de la mayor gravedad propia que se supone caracteriza a estos delitos pase ahora, precisamente a recaer de forma exclusiva en las finalidades con que se realizan, agravándose aún más los problemas que su ya comentada y controvertida definición ampliada va a generar. ${ }^{17}$

\footnotetext{
15 Sobre esta polémica figura y su controvertida inclusión en el concepto de terrorismo, véase, lo comentado, por ejemplo, por Cancio (2010a: 260 y ss.); Núñez (2013: 108 y ss.); Gómez (2010: 40) quien de hecho afirma que la existencia de dicha figura y su calificación como terrorista solo tiene un fundamento procesal, ya que permitía incrementar la pena de quienes cometen delitos con finalidades terroristas, sin tener que demostrar o acreditar su pertenencia a organización criminal o González (2006: 73) quien sí se manifestaba favorable a considerar dicho delito como verdaderamente terrorista.

${ }^{16}$ En este sentido, ya destacaba Cancio (2011: 660) que la reforma de estos conceptos realizada por la LO 5/2010 afirmaba en su propio preámbulo que la inclusión del vaporoso concepto de grupo terrorista quería atender a las peculiaridades de "determinados grupos o células terroristas de relativamente reciente desarrollo en el plano internacional", lo que era criticado por dicho autor, por entender que en realidad, la propia jurisprudencia había demostrado que no existía problema alguno para perseguir y castiga estas nuevas formas de organización en red, mediante la utilización del concepto clásico de organización terrorista.

17 De este modo, señala el propio Preámbulo de la LO 2/2015 que el tratamiento jurídico penal tradicionalmente establecido para bandas armadas como los GRAPO o ETA se había articulado sobre el eje de al definición de organización o grupo terrosita, castigando a quienes se integraban en ellas o les prestaban algún tipo de colaboración, afirmando, sin embargo, que si bien "El Código Penal no debe, en ningún caso, perder esa perspectiva de tipificación de las conductas articuladas en torno a organizaciones o grupos terroristas, (...) es evidente que las nuevas amenazas exigen la actualización de la normativa para dar cabida al fenómeno del terrorismo individual y a las conductas que constituyen la principal preocupación de la comunidad internacional, en línea con la Resolución 2178 del Consejo de Seguridad de Naciones Unidas anteriormente citada”, lo que ha llevado a que la nueva definición de los delitos de terrorismo, contenida en el nuevo art. 573 $\mathrm{CP}$, los delimite estableciendo que se tendrán por tales cualquier delito grave contra bienes tan esenciales, como la salud o la vida, entre otros, si se realiza con alguna de las finalidades que se mencionan en dicho artículo, sin exigir, por tanto que hubiesen de ser cometidos alguien que lo hiciese "perteneciendo, actuando al servicio colaborando con organizaciones o grupos terroristas...", tal y como hacía la anterior definición de dichos delitos, contemplada en el art. 572 ACP. Es precisamente, por ello, por lo que autores como Muñoz (2015: 789) han pasado a afirmar de forma rotunda que, tras la reforma de 2015, el núcleo de la definición del terrorismo lo constituye el tipo subjetivo, es decir, que los delitos de los que se trate se realicen con los fines de los que habla el art. 573.1 CP. En la misma línea se manifiestan, por ejemplo, Cano (2015b: 913) o Campo (2015: 14) quien señalaba que, si bien la innecesariedad del elemento estructural u organizativo del terrorismo se ha asumido ahora por cuestiones puramente prácticas y utilitaristas, quedando incluso reflejada en el propio tenor literal del Pacto de Estado que dio lugar a la citada reforma, en realidad, no podía erigirse en elemento esencial de su definición. Partidario, ya antes de la reforma, de la eliminación de la exigencia del denominado elemento estructural del terrorismo, se mostraba González (2007: 250) quien además destacaba como
} 
Galán - Nuevas formas de terrorismo, nuevos instrumentos penales...

Sorprende sin embargo que las peculiaridades que presenta la nueva forma de terrorismo de la que nos venimos ocupando no hayan movido ni un ápice al legislador de su afán punitivista frente a esta clase de delincuencia, viniendo de hecho la última reforma del Código Penal realizada con respecto a esta materia a dar una vuelta de tuerca más en la imparable espiral intensificadora que tradicionalmente ha caracterizado a la política criminal seguida con la misma. Así, se ha procedido de nuevo a incrementar de forma general y, en ocasiones de forma desproporcionada las penas previstas para las actuaciones terroristas -previendo incluso la aplicación de la muy cacareada y controvertida pena permanente revisable para los delitos de terrorismo que ocasionen una muerte en el nuevo art. 573 bis.1.1 $1^{\text {a }} \mathrm{CP}-{ }^{18}$ mientras que por otra parte se ha vuelto a endurecer su régimen de ejecución ${ }^{19}$ pese a que, como ya hemos señalado, resulta evidente que ambas medidas no solo son preventivamente ineficaces frente a esta nueva hornada de terroristas, sino que pueden resultar incluso contraproducentes frente a los mismos, ya que al permitir que se sancione a los autores de conductas en verdad leves con penas severísimas y completamente desproporcionadas a su gravedad objetiva por el mero hecho de haberlas realizado para respaldar los fines que las caracterizan como terroristas, se puede llegar a que se haga aparecer a quienes las padezcan como verdaderas víctimas de un sistema injusto y draconiano que les castiga tan severamente no por la gravedad de lo que hacen, sino por haberlo hecho para defender sus ideales, convirtiéndolos así en verdaderos "mártires" y ejemplos vivientes a seguir para aquellos que comparten sus ideas y su visión maniquea del mundo. ${ }^{20}$

Esto carece de cualquier sentido desde un punto de vista preventivo y nos hace pensar que tras esta nueva vuelta de tuerca punitiva no se encuentra en realidad una verdadera pretensión preventivo general negativa, sino una puramente preventivo general positiva que trata de dar una "falsa sensación de seguridad" a la ciudadanía o, lo que es incluso peor, una simple y burda manifestación del más puro y duro populismo punitivo que, como señala Cano Paños (2015b: 951), es el que posiblemente haya llevado al legislador a querer curarse en salud frente a las críticas que se le podrían dirigir si se producen atentados, para que nadie le pueda reprochar

el propio art. $55 \mathrm{CE}$, que da pie a la especial regulación antiterrorista, habla tanto de bandas como de elementos terroristas, lo que se refiere claramente a personas individuales.

18 Véase a este respecto lo comentado, por ejemplo, por Cano (2015b: 918 y ss.) o el mismo autor (2015a: 12).

${ }^{19}$ Llamativo, a este respecto, es el especialmente severo régimen de acceso a la libertad condicional establecido para los terroristas en los art. 90.8 y $92.2 \mathrm{CP}$, sobretodo si se pone en relación con lo establecido en los art. 78.2 y 78 bis. 3 CP, como señalan, por ejemplo, por Muñoz / García (2015: 627). Sobre el régimen general de acceso a la libertad condicional, véase, por ejemplo, lo comentado por Barquín (2015: 255 y ss.).

${ }^{20}$ En este sentido, señala Cancio (2008: 316 y ss.) que una de las estrategias del terrorismo es provocar las reacciones del Estado que le lleven a una escalada punitiva que dé pie a la rebelión popular, al tiempo que dé a los terroristas la condición de beligerante que le permita ampliar su influencia social, con lo que la escalada de dura represión ejercida por el poder contra los terroristas, termina convirtiéndolo en cómplice funcional de las pretensiones perseguidas por los terroristas. 
entonces que no hubiese sido previamente lo suficientemente duro o no hubiese hecho todo lo que estaba en su mano para tratar de evitar que se llegasen a cometer.

Ahora bien, todo lo anterior no supone que el legislador español no haya sido plenamente consciente de que las amenazas de penas de larga duración, por muy elevadas que sean y el endurecimiento de su posible ejecución, no resultan en modo alguno eficaces a la hora de prevenir y evitar los ataques que pueden realizar quienes constituyen el último eslabón del mecanismo terrorista yibadista, el que nos viene dado por quienes materialmente ejecutan los ataques terroristas incluso a costa de su propia vida.

De hecho ha sido dicha consciencia legislativa la que ha llevado a que la reforma realizada por la LO 2/2015, además de ampliar el posible campo de aplicación de los excepcionales mecanismos penales y procesales establecidos contra el terrorismo y de intensificar la respuesta punitiva frente al mismo, también haya venido a adelantar una vez más la posible intervención penal frente a las actuaciones que lo caracterizan, creando una serie de figuras de nuevo cuño -según se nos dice para atender directrices inter y supranacionales ${ }^{21}{ }^{21}$ que tratan de neutralizar el fenómeno terrorista en sus más primigenias manifestaciones, para lo cual persiguen y reprimen las iniciales actuaciones de captación, adiestramiento y adoctrinamiento, tanto pasivo como activo, de futuros terroristas en lo que supone un claro intento de prevenir los actos lesivos que dichos sujetos podrían llegar a realizar una vez preparados y entrenados, antes siquiera de que comiencen a darles ejecución.

Veamos a continuación cuáles son estos nuevos mecanismos y cómo interactúan tanto entre sí como con las figuras previamente existentes en nuestro ordenamiento.

\section{El castigo del adiestramiento o adoctrinamiento pasivo (art. $575 \mathrm{CP}$ )}

La primera de las nuevas figuras introducidas por la reforma en nuestro ordenamiento en su empeño de acabar con el mecanismo terrorista desde su mismo comienzo aparece contemplada en el nuevo art. 575.1 CP, donde se establece que "[s]erá castigado con la pena de prisión de dos a cinco años quien, con la

\footnotetext{
${ }^{21}$ En concreto, el propio Preámbulo de la LO 2/2015 afirma que "La Resolución del Consejo de Seguridad de Naciones Unidas 2178, aprobada el 24 de septiembre de 2014, recoge la honda preocupación de la comunidad internacional por el recrudecimiento de la actividad terrorista y por la intensificación del llamamiento a cometer atentados en todas las regiones del mundo. En el catálogo de medidas que constituyen la parte dispositiva de esta Resolución, aparece en el punto sexto un recordatorio de la Resolución 1373 (2001), en virtud de la cual todos los Estados miembros deben velar por el enjuiciamiento de toda persona que participe en la financiación, planificación, preparación o comisión de actos de terrorismo o preste apoyo a esos actos", mientras que posteriormente, también alude a la Decisión Marco 2002/475/JAI del Consejo de la Unión Europea, de 13 de junio de 2002, sobre la lucha contra el terrorismo, modificada por la Decisión Marco 2008/919/JAI, de 28 de noviembre de 2008, con fundamento de otras modificaciones realizadas en materia de terrorismo y, en especial, de la cuestionada ampliación de los fines que convertirán los delitos en terroristas.
} 
Galán - Nuevas formas de terrorismo, nuevos instrumentos penales...

finalidad de capacitarse para llevar a cabo cualquiera de los delitos tipificados en este Capitulo, reciba adoctrinamiento o adiestramiento militar o de combate, o en técnicas de desarrollo de armas quimicas o biologicas, de elaboración o preparación de sustancias o aparatos explosivos, inflamables, incendiarios o asfixiantes, o especificamente destinados a facilitar la comisión de alguna de tales infracciones."

Con ello se castiga como autor de un delito autónomo y consumado, no al que distribuye o difunde los contenidos adoctrinadores o al que entrena o adiestra a los futuros autores de delitos terroristas para que los cometan, sino a quien reciba instrucciones o informaciones adoctrinadoras o de entrenamiento de terceros y pretenda emplearlas para capacitarse para llevar a cabo delitos de terrorismo. Esto evidentemente amplía de forma significativa el número de conductas puramente preparatorias de delitos terroristas que podrán llegar a adquirir relevancia típica con respecto a la regulación anteriormente existente, ya que permitirá que el Derecho Penal pueda castigar, no solo a las actuaciones capacitadoras pasivas que se efectúen asistiendo a las prácticas organizadas para apoyar al terrorismo (castigadas como colaboración terrorista por el anterior art. 576.2 ACP y que continúa castigando como tal delito el nuevo art. 577.1 CP), sino también una amplia variedad de modalidades de adiestramiento o adoctrinamiento pasivo que se podrá recibir tanto de forma externa y desconectada a las organizaciones o grupos terroristas propiamente dichos, como de alguien que los hubiese suministrado sin tener siquiera intención de preparar a los destinatarios de sus enseñanzas para que pudieran cometer delitos terroristas.

Se abren así las puertas a que se pueda castigar a los futuros terroristas individuales por una amplia variedad de actuaciones meramente preparatorias y situadas todavía en fases muy alejadas a las del comienzo de la ejecución de los delitos que querían cometer.

Sin embargo, no parece que ello haya satisfecho las ansias expansionistas del legislador, como lo demuestra el hecho de que haya decidido establecer en el apartado 2 del mismo art. $575 \mathrm{CP}$ que “...con la misma pena se castigará a quien, con la misma finalidad de capacitarse para cometer alguno de los delitos tipificados en este Capitulo, lleve a cabo por si mismo cualquiera de las actividades previstas en el apartado anterior.", lo que convertirá en penalmente relevante incluso los meros actos de autoadiestramiento o autoadoctrinamiento pasivo que realice de forma individual y autónoma quien por ejemplo, busque por su cuenta contenidos instructores o adoctrinadores que le sirvan para prepararse para cometer cualquier delito de terrorismo y comience a utilizarlos con el fin de conseguirlo.

Nuevamente nos encontramos ante una figura que sanciona actuaciones que se desarrollan en momentos previos y muy alejados del comienzo de la ejecución de cualquier acto terrorista propiamente dicho, por lo que no puede sorprender que el referido precepto contemple y castigue como hacía el anterior conductas que, en principio, serían neutrales desde un punto de vista objetivo y 
que solo se convierten en delictivas por la concreta finalidad que persigue su autor con su ejecución.

En efecto, entrenarse militarmente, aprender a fabricar explosivos o simplemente buscar y consumir ideas islamistas por muy radicales que puedan ser, tanto si se hace de forma individual como con ayuda de terceros, solo será delito si se hace con la intención de capacitarse o prepararse para cometer posteriormente "cualquiera de los delitos tipificados en este capitulo", exigencia subjetiva que si bien restringe el ámbito de aplicación tanto de esta figura como de la anterior, al excluir de sus respectivos tipos de injusto, por ejemplo a aquellos actos de adiestramiento que se realicen con finalidades no delictivas ( $p$. ej. con finalidad puramente investigadora o por curiosidad) (Cortés 2015: 678) o a los que se efectúen para cometer delitos de naturaleza no terrorista (p. ej. para efectuar un asesinato común), al mismo tiempo también permitirá que dichas figuras se puedan aplicar a todo aquel que realice cualquiera de las conductas que mencionan tanto si las ejecuta con la finalidad de prepararse para cometer un acto terrorista individual y completamente desvinculado de un grupo u organización terrorista concreta, para integrarse en una de estas estructuras (art. 572.2 CP), como para simplemente colaborar de forma puntual con las mismas (art. $577 \mathrm{CP}$ ), abriéndose así la posibilidad de que se pueda llegar a castigar como autor de estos delitos en su modalidad consumada a quien tan solo se estaría preparando, con ayuda o individualmente, para cometer delitos que castigan a su vez actuaciones que, cuando se ejecuten, se desenvolverán también en el ámbito meramente preparatorio de los verdaderos atentados terroristas.

Se llegaría así a castigar como delito consumado un mero acto preparatorio de lo que no dejaría de ser sino otra actuación meramente preparatoria de la verdadera comisión o participación en un atentado terrorista, lo que supone un nuevo y no desdeñable adelantamiento de la intervención penal frente a estas últimas actuaciones, ya que abre un nuevo círculo concéntrico de relevancia penal respecto a las conductas previas al comienzo de la ejecución de los atentados terroristas propiamente dichos.

El adelantamiento de la intervención penal como se puede comprobar es enorme, pero aún lo será más si se tiene en cuenta que las figuras delictivas que venimos analizando definen y delimitan sus injustos típicos exigiendo que los actos de adiestramiento o adoctrinamiento a los que aluden se efectúen no "para cometer algín delito terrorista", como exigen por ejemplo los actos preparatorios punibles contemplados en el art. $579 \mathrm{CP}$, sino "con la finalidad de capacitarse para llevar a cabo cualquiera de los delitos tipificados en este capitulo", expresión normativa que, sin duda, determina que estos delitos se puedan considerar realizados y consumados cuando su autor por los motivos que sea, (p. ej. por una intervención policial) no llegue a comenzar con la ejecución del delito que quería cometer o ni siquiera consiga capacitarse como pretendía para poder hacerlo, pero que además también permitirá que se le pueda castigar por haber realizado las actividades de capacitación a las que alude, aún cuando las haya efectuado sin tener todavía una intención definida de 
Galán - Nuevas formas de terrorismo, nuevos instrumentos penales...

cometer un concreto delito terrorista, sino simplemente con la finalidad de prepararse para poder efectuar, como el propio precepto establece, cualquiera de ellos en general.

Así se deduce a nuestro juicio del propio tenor literal de los comentados preceptos y, en especial, de la peculiar configuración de sus respectivos elementos subjetivos del injusto que, como hemos dicho, contrasta con la utilizada en otros preceptos que contemplan verdaderos actos preparatorios de delitos terroristas concretos y también de que ambas figuras sancionen actuaciones tan distantes no solo del comienzo de la efectiva ejecución de los verdaderos atentados terroristas, sino incluso de la adopción de la decisión de cometer uno en concreto de entre ellos, como serían por ejemplo la referidas a la mera recepción y asimilación de ideas y creencias radicales (adoctrinamiento pasivo). Pero, además y sobre todo, respalda dicha interpretación el hecho de que las dos figuras comentadas establezcan para sus autores una pena (de 2 a 5 años) que no dependerá ni estará directamente relacionada con la prevista para los delitos que su ejecución supuestamente viniese a preparar, hecho que nos lleva a entender que nos encontramos en realidad ante unos delitos cuya realización no tiene por qué estar necesariamente dirigida a la comisión de otro concreto delito terrorista y, por tanto, convierte a estas figuras en delitos de mera actividad y peligro abstracto, completamente autónomos del resto de delitos terroristas y no como algunos afirman en figuras que vendrían simplemente a establecer unas nuevas y controvertidas modalidades preparatorias individuales y punibles respecto a su ejecución. ${ }^{22}$

Se haría así que los comentados delitos pudiesen castigar, por ejemplo a quien comenzase a entrenarse militarmente o iniciase su adoctrinamiento para estar listo para poder cometer algún delito terrorista en el futuro, sin tener todavía claro si utilizaría los conocimientos o la preparación que quería adquirir para matar a un tercero, secuestrarlo, poner una bomba, realizar un delito de daños terrorista o simplemente colaborar o integrarse en una organización o grupo terrorista, lo que sin duda convertirá a estas figuras en instrumentos represivos que pueden resultar tremendamente eficaces a la hora combatir las fases más iniciales de la nueva forma de terrorismo de la que nos venimos ocupando al permitir que se investiguen, se persigan y sancionen penalmente algunas actuaciones individuales que permanecían hasta ahora al margen de cualquier intervención penal por desarrollarse al margen de las clásicas organizaciones terroristas y no constituir ni poder siempre subsumirse en ninguno de los muy diversos actos preparatorios punibles de delitos terroristas concretos que se contemplan en nuestra legislación.

\footnotetext{
${ }^{22}$ En este sentido, señala Cano (2015b: 927 y 931) que la conexión de estas actividades delictivas y el futuro atentado debe producirse, precisamente, a partir de la intención delictiva del autor, por más que no sea necesario, sin embargo, que dicho sujeto haya planeado ya en detalle la futura acción terrorista a realizar, lo que los convierte en figuras que castigan actos preparatorios de los concretos delitos terroristas que se querría realizar y echaría por tierra el tradicional principio del Derecho penal que mantenía la impunidad de los actos preparatorios en el caso de autores individuales.
} 
Sin embargo para conseguirlo, a nuestro modo de ver dichas figuras han desdibujado de forma tan notable la lesividad objetiva propia de sus injustos típicos que será realmente difícil que la represión de su realización resulte compatible con las exigencias derivadas de los principios de intervención mínima y de proporcionalidad que deberían respetar el Derecho Penal de todo verdadero Estado de Derecho.

Así por ejemplo ¿resulta realmente acorde al primero de los principios mencionados que estas figuras vengan a castigar actuaciones tan alejadas de la verdadera puesta en peligro de bienes jurídicos concretos como las de empezar a estudiar textos salafistas para poder llegar a colaborar puntualmente con alguna organización terrorista defensora de dichas ideas?, ${ }^{23}$ ¿Respeta además las exigencias mínimas derivadas del principio de proporcionalidad que castiguen con la misma pena, cuando menos en abstracto, a quien no se ha decidido a cometer un concreto delito terrorista, pero está decidido a ejecutar alguno en el futuro y se prepara para poder hacerlo y a quien se instruye estando ya resuelto a ejecutar por su propia mano un concreto y cercano delito?, ¿O que se haga lo mismo con quien se quiere preparar para cometer un atentado con múltiples víctimas mortales que a quien solo pretende cometer unos daños informáticos del $264 \mathrm{CP}$ con fines terroristas?

Pero por otra parte ¿qué haremos entonces cuando el autor de estas conductas cometa posteriormente uno o varios de los delitos para los que se estaba capacitando al realizarlo?, ¿Entenderemos, como en principio podría pensarse, que la apreciación de estos últimos delitos absorbería la de la figura que venimos analizando, consumiéndola? (Cortés 2015: 679), ¿O, por el contrario y como parece indicar su naturaleza de delitos autónomos y la amplitud del peligro que genera la realización de estas nuevas figuras, tendremos que considerar que ello solo se podrá apreciar cuando el peligro criminal generado con su ejecución se vea completamente absorbido y sea por tanto castigado por la apreciación del concreto delito posteriormente realizado como sucederá cuando concurran con un delito cuya ejecución determinaría la absoluta neutralización del terrorista (p. ej. un atentado suicida frustrado) o con otra figura de peligrosidad similarmente amplia a las del art. $575 \mathrm{CP}$ como sería, por ejemplo la de integración en organización o grupo terrorista teniendo que apreciarse en el resto de supuestos el correspondiente concurso de delitos entre el que castiga las actuaciones de capacitación realizadas y el posteriormente ejecutado, ya que la comisión del primero podría permitir que su autor pudiese volver a efectuar posteriormente otros delitos diferentes e incluso más graves que el que había llevado a cabo y generaría un peligro que no se vería absorbido por este?

\footnotetext{
23 De hecho, y en este sentido, señala Cano (2015a: 27 y ss.) que en estos delitos se llega a castigar ataques que todavía se mantienen en el más estricto fuero interno del sujeto que los realiza, olvidándose así de que lo que determina y puede fundamentar su castigo es la peligrosidad objetiva de los actos dirigidos a consumar delitos.
} 
Galán - Nuevas formas de terrorismo, nuevos instrumentos penales...

Todas estas cuestiones esconden, a nuestro modo de ver, otra mucho más de fondo: ¿Realmente las figuras que venimos analizando castigan al sujeto por el todavía muy lejano y difuso peligro que genera su conducta capacitadora para el amplio e indeterminado conjunto de bienes jurídicos a los que podría llegar a afectar con su futura actuación o en realidad lo que sucede es que su creación ha dejado al margen la valoración de tales parámetros tradicionalmente delimitadores, al tiempo que legitimadores de la intervención penal y de su intensidad (bien jurídico, lesividad, etc...), para sustituirlos por el mucho más cuestionable y criticable referido a la peligrosidad subjetiva que, como señala algún autor alemán, presentan quienes como los que se plantean ser terroristas se salen al hacerlo de los márgenes de seguridad cognitiva que exigimos a los sujetos para tratarlos como verdaderas personas o ciudadanos y, precisamente por ello, pasan a ser considerados como enemigos o meras fuentes de peligro que hay que inocuizar y neutralizar a cualquier precio ? $^{24}$

Si todo lo anterior resulta ya de por sí harto cuestionable, aún lo es más que el legislador haya decidido adelantar un poco más la intervención penal frente a las actuaciones de autoadoctrinamiento y autoadiestramiento pasivo al castigar con la misma pena que a quienes realicen las actuaciones anteriormente comentadas, tanto al que simplemente se traslade o establezca en un territorio extranjero controlado por un grupo u organización terrorista con la finalidad, eso sí, de adiestrarse o adoctrinarse para cometer delitos terroristas, como aquel que "...con tal finalidad, acceda de manera habitual a uno o varios servicios de comunicación accesibles al público en linea o contenidos accesibles a través de internet o de un servicio de comunicaciones electrónicas cuyos contenidos estén dirigidos o resulten idóneos para incitar a la incorporación a una organización o grupo terrorista, o a colaborar con cualquiera de ellos o en sus fines" o simplemente "... adquiera o tenga en su poder documentos que estén dirigidos o, por su contenido, resulten idóneos para incitar a la incorporación a una organización o grupo terrorista o a colaborar con cualquiera de ellos o en sus fines."

Con ello se nos dice que ya ni siquiera habrá que llegar a probar que el sujeto en cuestión haya comenzado a autoadiestrarse o adoctrinarse para poder castigarle como si lo hubiese hecho y, por tanto, hubiese completado el injusto castigado en el art. 575.2 de nuestro Código Penal, bastando para poder hacerlo con que se constate que viajó a un país sospechoso, accedió de forma habitual a determinados sitios de internet o simplemente poseyó determinados documentos considerados como peligrosos, teniendo intención de prepararse para cometer delitos terroristas.

Se castigan así actuaciones cuya realización, por definición no supone que quien las efectúe se haya empezado a adoctrinar o adiestrar con el fin de

\footnotetext{
${ }^{24}$ Sobre esta concepción y, en concreto, sobre la inclusión en el concepto de "enemigo" de los terroristas, por ser unos sujetos que, al haberse alejado de forma duradera del sistema jurídico, no darían las garantías cognitivas mínimas de respeto general a las normas de convivencia social que permitirían considerarles como personas, véase, lo comentado lo Jakobs (2006: 33 y ss.).
} 
capacitarse para cometer delitos terroristas (viajar al extranjero, no entrenarse o adiestrarse allí; poseer documentos adoctrinadores, no leerlos ni estudiarlos), pero que sin embargo y pese a ello, se sancionan con la misma pena que si realmente lo hiciesen; decisión legislativa que, si bien es perfectamente coherente con la pretensión de utilizar el Derecho Penal para luchar por todos los medios contra las conductas iniciales de capacitación de terroristas, supone establecer de facto una suerte de presunción legal iuris et de iure contra reo respecto a la realización de las verdaderas actuaciones de autoadiestramiento o autoadoctrinamiento que, como bien señala Muñoz Conde (2015: 800 y ss.) parece volver a introducir en nuestro ordenamiento la vieja y denostada figura de los delitos de mera sospecha, haciendo que las comentadas previsiones legales resulten difícilmente compatibles con nuestra constitución . ${ }^{25}$

Ahora bien el legislador, en su empeño por perseguir y prevenir los atentados terroristas antes de que se comiencen a ejecutar, no solo ha centrado su atención en la sanción de quienes son convencidos, captados o entrenados o se preparan por sí mismos para cometerlos, sino que también y como no podía ser de otra forma ha vuelto a prestar especial atención a las actuaciones realizadas por quienes les adoctrinan o preparan de forma activa para que puedan llegar a realizarlos. Esto es a quienes realizan actividades de entrenamiento, captación, adoctrinamiento o adiestramiento activo; sujetos estos que efectúan actividades que han sido normalmente perseguidas y sancionadas mediante determinadas figuras delictivas más o menos tradicionales (inducción al delito, provocación, integración o colaboración con organizaciones terroristas, etc...), a las que la reforma ha venido a añadir algunas de nuevo cuño, dando así lugar a un panorama normativo abigarrado, cuestionable y de difícil interpretación, coordinación y justificación, a cuyo estudio vamos dedicar las siguientes líneas.

\section{La compleja regulación penal de la captación, el adiestramiento o el adoctrinamiento activo}

Evidentemente la forma general de castigar a aquella persona que comunica a un tercero un mensaje dirigido a conseguir que este se decida a cometer un delito terrorista, sea el que sea, será considerarle bien como inductor, bien como cómplice psíquico de dicho delito ${ }^{26}$ mientras que a aquel que le instruya o enseñe los conocimientos y técnicas que necesitaría para poder llevarlo a cabo se le podrá tener como cómplice o, todo lo más, como cooperador necesario de su realización;

\footnotetext{
25 Sobre la categoría de los delitos de sospecha y sus problemas de constitucionalidad, resulta interesante la lectura del trabajo de García (1993: 630 y ss.) donde se señala que lo que caracteriza a estas figuras es precisamente el hecho de que la existencia de ciertos elementos del tipo de un delito se infiere a partir de la concurrencia de otro u otros, estableciéndose así una cuestionable presunción (iuris tantum o iuris et de iure) con respecto a su concurrencia que trata de evitar las dificultades probatorias que algunas figuras presentan.

26 Sobre la concreta delimitación de ambas formas de participación intelectual en el delito ajeno, véase, por ejemplo, lo comentado por Gómez (1995: 172 y ss.).
} 
Galán - Nuevas formas de terrorismo, nuevos instrumentos penales...

calificaciones estas que sin embargo requerirán que el autor al que se induce o ayuda a cometer un delito comience, cuando menos, a ejecutarlo.

Precisamente por ello y dado que uno de los objetivos primordiales de la política criminal en materia de terrorismo es, y siempre ha sido, el de hacer factible que el Derecho Penal pueda prevenir la comisión de los gravísimos atentados propios de esta forma de criminalidad, interviniendo incluso antes de que el tercero al que se incite o se instruya para cometerlos llegue siquiera a decidirse a dar comienzo a su ejecución, no puede sorprender que el legislador optase hace ya tiempo por castigar en relación a estos delitos las formas de participación intentada descritas en los artículos 17 y $18 \mathrm{CP}$; previsión que continúa manteniendo la última reforma y que se contiene en el actual artículo 579.3 CP donde expresamente se prevé el castigo de la provocación, la proposición y la conspiración de "alguno de los delitos regulados en este capitulo".

Será este precepto el que permitirá, por ejemplo y atendiendo a lo establecido en el art. $18 \mathrm{CP}$, que el Derecho Penal pueda sancionar como provocadores a quienes se dedican a utilizar internet o cualquier medio de comunicación de masas para difundir contenidos que están directa y manifiestamente dirigidos a incitar a sus posibles receptores a cometer un delito terrorista aún cuando estos últimos sujetos, por los motivos que fuesen, no solo no comenzasen a ejecutarlo, sino que ni siquiera hubiesen llegado conocer o ser convencidos por el mensaje que trataba de motivarles para que lo realizasen. ${ }^{27}$ Lo mismo sucederá con quienes simplemente realicen actuaciones incitadoras de forma pública o ante una concurrencia de personas conforme a lo establecido en el art. $18 \mathrm{CP}$ lo que nos hace pensar que carece de todo sentido que el nuevo apartado 2 del artículo 579 del Código Penal haya venido expresamente a castigar de forma separada y con la misma pena prevista para la provocación a quien "públicamente o ante una concurrencia de personas, incite a otros a la comisión de alguno de los delitos de este Capitulo", ya que al poder incardinarse tal conducta por definición en el concepto general de provocación resulta del todo innecesaria esta segunda y separada tipificación.

Ahora bien, algo diferente sucede sin embargo y tras la reforma, con la otra conducta que el nuevo art. 579.2 CP contempla al final de su descripción. Esto es con los casos en los que el sujeto solicite directamente a otro, a un destinatario individual y definido, que cometa un determinado delito terrorista.

Estos supuestos, a juicio de un importante sector doctrinal, podían ser castigados antes de la reforma operada por la LO 1/2015 mediante la apreciación

\footnotetext{
${ }^{27}$ En este sentido, señalaba Bernal (2011: 70) que la previsión de la provocación respecto a delitos terroristas determinaba que "...cualquier mensaje o consigna que implique una incitación directa a un delito de terrorismo no seguido de su comisión ya está contemplado en el definición de la provocación”. Sobre los requisitos y límites de la provocación como forma de participación intentada, véase, lo comentado, por ejemplo, por Rebollo (1997: 78 y ss.) o Barber (2004: 238 y ss.), entre otros.
} 
de la figura de la proposición que, como hemos visto, también sanciona el vigente art. $579 \mathrm{CP}$ en su tercer apartado, ya que consideraban que dicha forma de codelincuencia intentada definida en el entonces vigente art. 17 ACP castigaba a quien realizase una conducta dolosa de inducción idónea dirigida a convencer a su destinatario individual para que cometiese un concreto delito que, sin embargo, no se viese seguida por su efectiva ejecución por parte de dicho sujeto (Barber 2004: 206); postura que, no obstante, contrastaba con la sostenida por quienes señalaban que la comentada descripción general de la proposición en realidad solo permitiría castigar a quien estando decido a cometer un delito por sí mismo -lo que lo convertiría en su verdadero dominador o autor cuando lo comenzase a realizar-, incitaba a otro a ejecutarlo junto a él, actuando por tanto este último sujeto en caso de aceptar la propuesta como mero partícipe o, todo lo más, como coautor del delito en cuestión cuando se llevase a cabo, ${ }^{28}$ algo que evidentemente dejaría al margen de esta forma de codelincuencia intentada a las actuaciones meramente preparatorias de la inducción individual de las que habla el nuevo art. 579.2 CP in fine.

Precisamente esta última y más restrictiva interpretación es la que a nuestro modo de ver ha encontrado definitivo respaldo por parte del legislador tras la reforma del artículo 17 CP realizada por la LO 1/2015, ya que al establecer la misma proposición "...cuando el que ha resuelto cometer un delito invita a otra u otras persona a participar en él" y no como hacía su anterior versión, cuando quien estando "... resuelto cometer un delito invita a otra u otras personas a ejecutarlo" se deja definitivamente claro que solo podrá considerarse y castigarse como propositor a quien, estando decidido a cometer por sí mismo un delito, invita (no incita) a otros no a que lo ejecuten, sino a que simplemente se unan o "participen" en su realización, esto es a que le ayuden a cometer el delito que él pretendía efectuar directamente, actuando por tanto como su verdadero dominador y autor. ${ }^{29}$

\footnotetext{
28 Así, por ejemplo, Rebollo (1997: 51 y ss.) quien consideraba que "al admitir que el proponente está resuelto a intervenir con actos ejecutivos descartamos implícitamente la opción de que en el seno de la proposición tenga cabida la inducción intentada, ya que es inherente a la condición de inductor que éste no sea autor, es decir, que no tome parte directa en la ejecución del hecho", lo que le llevaba a considerar que la proposición en realidad no era sino una suerte de invitación a la conspiración, luego una propuesta de coautoría, que a diferencia de la conspiración no es aceptada por su destinatarios. También se decanta por esta visión restrictiva, por ejemplo, Campo (2000: 51 y ss.).

${ }^{29}$ De otra opinión, sin embargo, Mir (2015: 353) quien, pese al cambio legislativo producido, sigue manteniendo que la proposición continúa castigando "la inducción no seguida de ejecución", ya que considera que al castigar el vigente art. 28 CP como autor de un delito no solo a quienes los ejecutan o realizan, sino también a quienes ayudan necesariamente o inducen a otros a ejecutarlo, habrá que continuar entendiendo que haber resuelto cometer un delito, tal y como exige el art. 17.2 $\mathrm{CP}$ al propositor, no supone tener que querer ejecutarlo como autor, dado que cometer el delito significa algo más amplio que ejecutarlo. Esto supone, a nuestro modo de ver, olvidar que, en realidad, lo que ha cambiado en la nueva redacción del art. 17.2 CP no es la exigencia de que el que propone quiera tomar parte en la comisión delictiva, sino el hecho de que exija que dicho sujeto tenga que invitar a terceras personas a "participar" en el delito que va a cometer y no que les invite "a ejecutarlo" como hacía antes. Con ello, se reduce la proposición a aquellos actos en los que la contribución que se pretende obtener de su destinatario sea siempre accesoria o, todo lo más, coadyuvante de aquella que pretendía efectuar directamente quien proponía realizar el delito, con lo
} 
Galán - Nuevas formas de terrorismo, nuevos instrumentos penales...

Ello supone que el expreso castigo de la proposición contenido en el art. 579.3 CP no pueda ser ya utilizado bajo ningún concepto para perseguir y sancionar penalmente a quienes realicen actos no exitosos de mera inducción individual o personal de los delitos de terrorismo sin intención alguna de convertirse en autores o coautores de los mismos, con lo que cobra pleno sentido que el legislador haya decidido castigar de forma expresa la ejecución de las actuaciones meramente incitadoras personales o individuales e intentadas en el apartado 2 del referido artículo, para evitar así que dicho tipo de peligrosas actuaciones se mantengan en el ámbito de lo penalmente irrelevante, por lo menos mientras aquel al que se dirijan (el solicitado) no comience a efectuar el delito que se le pidió que cometiese.

Ahora bien, el empeño del legislador en castigar los meros intentos de incitar a terceros para que cometan delitos terroristas no terminó aquí, sino que también le llevó a incluir en el primer apartado del artículo que venimos comentando la posibilidad de que se pueda llegar a castigar con las mismas penas que a los propositores a los provocadores o a los meros inductores individuales intentados de los que habla el art. 579.2 in fine CP, a quien "...por cualquier medio, difunda públicamente mensajes o consignas que tengan como finalidad o que, por su contenido, sean idóneos para incitar a otros a la comisión de alguno de los delitos de este capitulo".

Nos encontramos ante un precepto que castigará tanto la difusión pública de mensajes o contenidos que tengan por "finalidad" la de incitar a sus destinatarios a cometer algún delito de terrorismo, esto es que estén orientados o dirigidos por quien los publica a producir dicho resultado en tales sujetos y se hayan difundido, por tanto con un dolo que abarcará la comisión por su parte del delito que pretendían incitar, como la de aquellos otros que simplemente se manifiesten como idóneos para que sus receptores se decidan a efectuarlo -expresión esta última que indudablemente abrirá las puertas a que esta figura pueda también castigar a quien difunda cualquier mensaje que resulte objetivamente adecuado, desde un punto de vista ex ante- para generar la idea en quienes lo reciban de cometer algún delito terrorista y lo haga teniendo conocimiento de tal cualidad del contenido, aunque no pretendan dar lugar con su publicación a la comisión del delito en cuestión por parte de sus posibles destinatarios. Esto es, aunque lo haya publicado sin actuar con la finalidad o dolo

que se obliga a este (al propositor) a tener que actuar con intención de cometer el delito actuando como su autor o, cuando menos, como coautor y no como un simple inductor, produciéndose así precisamente aquella restricción referida al papel del destinatario de la proposición que el propio Mir (2002: 337) decía que faltaba en la versión anterior a la reforma de esta forma de participación intentada, para excluir de su posible ámbito de aplicación a las meras inducciones intentadas (que castigase al que invitase a "tomar parte en la ejecución", esto es, a participar y no a ejecutar como hacía el anterior texto del art. $17 \mathrm{CP}$ ). 
directo de inducir a un tercero a cometer un delito terrorista, pero sí con un dolo que abarcase la idoneidad del contenido para poder llegar a hacerlo. ${ }^{30}$

La ampliación típica que la redacción de esta figura conlleva con respecto a la tradicional delimitación de la provocación, es tan evidente como cuestionable.

Lo es a primera vista, porque al no exigir el nuevo art. 579.1 CP que los mensajes o consignas publicados tengan que incitar directamente, esto es de forma clara y manifiesta a cometer algún delito, como exigiría la inducción o la provocación, ${ }^{31}$ sino castigar la publicación de cualquier contenido que tenga por finalidad o resulte idóneo para incitar a sus receptores a cometerlos, se permite que esta figura pueda sancionar la distribución de contenidos que busquen tal resultado o presenten dicha peligrosidad aún cuando lo hagan de forma indirecta o implícita lo que, sin duda, difuminará de forma notable los caracteres que tradicionalmente habían delimitado a los mensajes incitadores penalmente relevantes, ya que resulta evidente que un mismo mensaje que no promueva de forma directa, manifiesta o explícita a cometer delitos de terrorismo, podrá sin embargo considerarse idóneo y

30 Esto último contrasta con el dolo exigido por la inducción, como forma de participación delictiva general que, tal y como señalan Gómez (1995: 402 y ss.), aunque sea eventual, tendrá que abarcar y tener un doble objeto de referencia. Por una parte, el nacimiento de la resolución delictiva en el autor inducido y por otra, no solo la realización por parte de este último sujeto del delito que se le quería incitar a realizar, sino la consumación de dicho delito; dolo que a nuestro modo de ver, también habrá de darse en la provocación del art. $18 \mathrm{CP}$, para poder apreciarla, ya que, entre otras cosas, solo así se entenderá, a nuestro juicio, que el segundo apartado in fine del comentado precepto afirme que la provocación de un delito seguida de su perpetración se castigará como inducción, lo que evidentemente requeriría que dicho resultado haya sido abarcado por el dolo del provocador que vaya a responder de él.

${ }^{31}$ De hecho, y como señala Bernal (2011: 70) la Exposición de Motivos de la LO 5/2010 que vino a introducir la figura predecesora de la que venimos comentando, precisamente afirmaba que la misma estaría referida a mensajes o consignas que no necesariamente consistiesen en "resoluciones manifestadas de delito", lo que se corresponde perfectamente con que este precepto no aluda a mensajes "directamente" incitadores, sino que tengan la finalidad o sean idóneos para incitar a cometer algún delito terrorista. Sobre la concreta interpretación de lo que debería entenderse por la expresión "directamente" utilizada tanto por la definición general de la inducción del art. 28 CP, como por la de la provocación del art. $18 \mathrm{CP}$, existe una viva polémica doctrinal, considerando algunos autores que la inclusión del comentado adverbio en el primero de los referidos preceptos supone la exigencia de que el contenido o mensaje incitador del inductor se dirija de forma personal del mismo al autor, como hacía GÓMEZ (1995: 114) en relación a la regulación de la inducción y la provocación previa al CP de 1995 o hace con respecto al actual Muñoz / García (2015: 472), mientras que otros, como Rebollo (1997: 90); Barber (2004: 252) entendían en relación con los actos de provocación del art. 18 CP que por definición se realizarán a través de medios de comunicación masivos y, por tanto, no de forma personal o privada, que dicha expresión excluirá de dichos comportamientos penalmente relevantes a las incitaciones vagas, imprecisas o indefinidas; postura está que consideramos la más acertada y que también debe predicarse con respecto a la inducción, lo que dotará de coherencia a la utilización del referido adverbio en ambos preceptos, pero además y por lo que a nosotros concierne, hará que cobre pleno sentido la introducción de un precepto como el que venimos analizado, el contenido en el art. 579.1 CP, que vendría a castigar precisamente la difusión de contenidos idóneos para incitar a sus destinatarios a cometer delitos, pero que, como ya hemos señalado, y a diferencia de los que castiga la provocación propiamente dicha, no tendrán que ser clara y expresamente incitadores a la comisión de delitos. 
Galán - Nuevas formas de terrorismo, nuevos instrumentos penales...

podrá utilizarse con la intención de inducir a cometerlos dependiendo de factores tales como el concreto momento en que se produzca su publicación o cuáles pudiesen ser en concreto sus destinatarios, dado que, sin duda no es indiferente para valorar la peligrosidad o idoneidad inductora que, por ejemplo podría tener un mensaje radicalmente crítico con el Estado o con sus cuerpos y fuerzas de seguridad si se difunde cuando dichas instituciones acaban de realizar o se encuentran insertas en una controvertida operación militar y se dirige a quien comparte y apoya los ideales sostenidos o medios utilizados por los que promueven la "guerra santa" contra las mismas, que si se difunde en un contexto histórico diferente y se destina a quien no solo no los comparte, sino que los rechaza de forma tajante.

La indeterminación típica que ello genera cuando hablamos de mensajes difundidos de forma pública, como son todos aquellos de los que se ocupa el art. $579.1 \mathrm{CP}$, es indudable (Cano 2015b: 945). ${ }^{32}$ Así, por ejemplo, ¿cuál de los posibles destinatarios del mensaje habrá de servir para fijar la peligrosidad o idoneidad inductora que lo convertiría en típicamente relevante?, ¿Habrá que tomar como parámetro al "hombre medio"?, ¿O, por el contrario, habrá que entender que, precisamente por encontrarnos ante actos de distribución o difusión pública tendrá que partirse de que siempre podrá haber entre sus posibles destinatarios alguno de los que resultan especialmente sensibles a su mensaje incitador?

Podría pensarse que en realidad y tal como afirmaba algún autor en nuestra doctrina con relación a la versión previa del precepto del que nos venimos ocupando (Bernal 2011: 68) la amplia redacción dada al mismo por nuestro legislador solo trataría de dar respuesta a la exigencia comunitaria introducida en el artículo 3 de la Decisión Marco 2002/475/JAI por la modificación que del mismo hizo la posterior Decisión Marco 2008/919/JAI, que obligaba a todos los Estados miembros de la Unión Europea a castigar la provocación como delito ligado a actividades terroristas, entendiendo como tal "...la distribución o difusión pública, por cualquier medio, de mensajes destinados a inducir a la comisión de cualesquiera de los delitos enumerados en el articulo 1, apartado 1, letras a) a b), cuando dicha conducta, independientemente de que promueva o no directamente la comisión de delitos de terrorismo, conlleve el riesgo de comision de uno o algunos de dichos delitos", lo que como bien señaló en su día Bernal del Castillo (2011: 67) dejaba muy claro que la provocación que todos los Estados debían castigar "... se trata de una conducta dolosa, destinada a inducir a uno de los delitos de terrorismo, independientemente de que promueva o no directamente la comisión de delitos concretos, siempre y cuando conlleve el riesgo de comisión de uno o de algunos de dichos delitos".

\footnotetext{
32 Críticos con la anterior redacción de este precepto también se mostraban Cancio (2011: 665) calificando la tipificación de lo que denominaba como "delito de propaganda" de "vaporosa y lesiva con el principio de legalidad" y Bernal (2011: 72) quien la tildaba de inconstitucional por entender que su indeterminación típica era incompatible con los principios de seguridad jurídica y el principio de legalidad penal.
} 
Sin embargo esta posible interpretación todavía ampliaría más el número de preguntas referidas a este precepto dotadas de una difícil respuesta.

Así por ejemplo, si la idoneidad inductora del mensaje típico del art. 579.1 CP puede estar referida, tal como parece exigir la recoger la comentada Decisión Marco, a la incitación general a cometer delitos terroristas y no necesariamente a uno de ellos concreto y determinado, ¿cómo podremos valorar su existencia teniendo un referente tan amplio y variado como el que nos fijan los muy variopintos delitos de terrorismo? Y por otra parte, ¿qué pasará entonces cuando el contenido pueda ser idóneo desde un punto de vista ex ante para incitar a cometer un grupo determinado de delitos terroristas (p. ej. unos daños y unas lesiones) y quien lo difunda abarque en su dolo dicho riesgo?, ¿Tendremos que considerar que ha efectuado un único delito de difusión pública de mensajes terroristas del art. $579.1 \mathrm{CP}$, como parecía indicar la redacción del precepto comunitario en el que parece tener origen, o habrá de entenderse por el contrario que se debería condenar a su difusor de forma separada por cada una de las incitaciones a cada uno de los concretos actos delictivos que podría llegar a generar?

Hay que señalar frente a todas estas cuestiones que si bien es perfectamente posible que al introducir el precepto que precedió al ahora comentado en la reforma penal realizada en el año 2010 (el contenido en el anterior art. 579.1. segundo párrafo CP), el legislador buscase precisamente atender a lo exigido por la referida Decisión Marco, abriendo así las puertas a que nuestro sistema penal pudiese castigar los actos públicos de incitación indirecta (es decir, no expresa o clara, sino implícita o no manifiesta) y genérica (esto es, orientados o adecuados para fomentar la comisión de cualquiera delito terrorista en general), resulta incuestionable que tras la modificación realizada sobre la comentada figura por la LO 2/2015, su previsión solo podrá cumplir ya parcialmente con tal cometido, dado que si bien podrá continuar castigando los actos de incitación pública no manifiesta o directamente dirigidos a incitar a cometer un delito terrorista, pero que se difundan con la finalidad o resulten idóneos para incitarlo, no podrá hacerlo sin embargo, con los que tiendan a provocar la comisión de delitos terroristas en general, puesto que, al determinar la nueva redacción del art. $579.1 \mathrm{CP}$ que el mensaje difundido tiene que tender o ser idóneo "para incitar a terceros a la comisión alguno de los delitos terroristas" y no de "cualquiera" de ellos como hacía su predecesor y establecer además la pena que le habría de imponer a quien lo difundiese, atendiendo a la que le habría de corresponder al concreto delito terrorista que su actuación tendiese o pudiese llegar a incitar y no de forma completamente independiente a dichas figuras, como hacía aquel, se deja completamente claro que nos encontramos ante un precepto que solo castigará actuaciones accesorias, dependientes y por tanto claramente preparatorias de un concreto y determinado delito terrorista.

No bastará por tanto, con que se publiquen mensajes que creen una abstracta situación o clima que podría llevar a sus receptores a decidirse a cometer uno o varios delitos terroristas todavía no determinados para poder apreciar este 
Galán - Nuevas formas de terrorismo, nuevos instrumentos penales...

delito. ${ }^{33}$ Para hacerlo será necesario además que el mensaje difundido, por más que no suponga la directa y expresa propuesta de cometer un delito concreto, sí incremente el riesgo, desde un punto de vista ex ante de que alguno de sus posibles destinatarios pueda decidirse a realizar un determinado y predecible delito terrorista, lo que tendrá dos importantes efectos con respecto a los problemas anteriormente planteados.

Por una parte y en primer lugar delimitará los mensajes o contenidos cuya difusión o publicación podrá ser castigada por esta figura, ya que al exigirse que estos tengan que estar dirigidos o ser idóneos para dar lugar a la realización de un concreto y definido delito terrorista, excluirá de su ámbito típico a todos aquellos mensajes que por muy radicales, rechazables o incendiarios que puedan ser no resulten previsiblemente adecuados para poder generar la comisión de un delito terrorista concreto y determinable en el mismo momento en que se publicaron. No bastará por tanto, con las incitaciones genéricas a "luchar contra el Estado" o a "combatir a los opresores"; mensajes que si bien pueden generar un riesgo genérico de producción de delitos terroristas, en la mayoría de los casos no permitirán pronosticar, desde un punto de vista ex ante, qué concreto delito podrían llegar a provocar.

Para apreciar el art. 579.1 CP la publicación realizada tendrá que recaer sobre un mensaje que por ejemplo, tras una intervención policial con víctimas mortales entre los terroristas, dijese que habría que "bacer sentir a quien la realizó el mismo dolor que habian ocasionado con su ataque"; mensaje este que por más que no contenga una propuesta directa, manifiesta o expresa de cometer un delito de homicidio terrorista contra el policía en cuestión, como exigiría la provocación, sí que incrementará de forma pronosticable y previsible el riesgo de comisión de tal delito y no de cualquier otro posible delito terrorista, lo que permitirá que la figura ahora analizada pueda castigar a quien lo publique tanto si lo hace con intención de incitar a cometer dicho homicidio, como si lo hubiese hecho sin tal finalidad o no se pudiese demostrar que lo había hecho con la misma, pero sí que había sido plenamente consciente de que su mensaje podría llegar a incitar a sus destinatarios a cometerlo.

Pero además y en segundo lugar, el hecho de que el injusto propio de la figura actualmente analizada solo contemple y castigue las conductas comunicativas generadoras del peligro de comisión de un único, pronosticable y concreto delito terrorista y no de un grupo indeterminado o numeroso de ellos,

\footnotetext{
33 En esto se diferencia claramente la nueva configuración típica de esta figura de su anterior delimitación, ya que, al exigir el art. 579.1 CP que el mensaje o consigna difundido tenga por finalidad o sea objetivamente idóneo para inducir a cometer aquel delito terrorista que establecerá el marco punitivo desde el que se determinará la pena aplicable a quien realice su publicación, ya no bastará para poder apreciar su comisión con que el mensaje en cuestión conlleve el riesgo de generar un caldo de cultivo adecuado para dar lugar a la comisión de delitos de terrorismo en general, como señalaba Bernal (2011: 70) con respecto a la anterior redacción de este precepto, sino que será necesario que se produzca una publicación que esté conectada objetiva y subjetivamente con la realización de un acto terrorista futuro, concreto y determinado.
} 
también llevará a que si el mensaje publicado tendiese o fuese idóneo para dar lugar a la realización acumulada y no alternativa por parte de sus destinatarios de varios de dichos delitos perfectamente predecibles y definidos y fuese además publicado por alguien que abarcase en su dolo dicha circunstancia, ${ }^{34}$ se le tenga que responsabilizar por tantas incitaciones delictivas del art. 579.1 CP como delitos terroristas concretos podría y sabría o querría llegar a generar con su actuación, mediante la apreciación del correspondiente concurso ideal de delitos entre las incitaciones de cada uno de dichos delitos terroristas.

Habrá que considerar por tanto que, si bien el comentado precepto del Código Penal puede servir para castigar las incitaciones indirectas, implícitas o no manifiestas de las que hablaba el art. 3 la modificada Decisión Marco 2002/475/JAI, tanto si se realizan con el fin de incitar a cometer un delito terrorista, como si se hacen simplemente teniendo conocimiento de que la conducta efectuada era adecuada para producirlo, no podrá sin embargo hacerlo con los actos de incitación genérica que dicha disposición comunitaria también obligaba a sancionar.

Podría pensarse sin embargo que esto se debe a que, en realidad nuestro código contempla desde hace tiempo una figura que podría castigar algunas de las más graves manifestaciones de incitación genérica indirecta a cometer delitos de terrorismo. Se trata, en concreto, del delito de enaltecimiento o justificación públicos de los delitos de terrorismo contenido en el art. $578 \mathrm{CP}$; una figura que, a juicio de algunos autores, no describe ni sanciona una simple modalidad específica de la apología del art. $18 \mathrm{CP}$-lo que llevaría a que solo castigase actos constitutivos de una provocación, esto es, de incitaciones públicas directas e intentadas a cometer delitos concretos,$-{ }^{35}$ sino que habría introducido en nuestro ordenamiento un verdadero "delito de clima" que sancionaría la difusión de las ideas que generen un entorno social de hostilidad hacia determinados colectivos, instituciones o personas, que podría llevar a que quienes reciban dichos mensajes de odio y vivan en dicho entorno se decidiesen a realizar cualquier clase de delito terrorista contra las mismas, por más que no les induzca expresamente a ejecutarlos ni se pueda siquiera predecir, cuando se realiza su difusión, cuál de dichas figuras en concreto podría llegar a provocar. ${ }^{36}$

\footnotetext{
34 Respecto a la diferencia entre este dolo que podríamos denominar como "dolo acumulativo" y el "dolo alternativo" y las implicaciones concursales de la apreciación de uno u otro en la realización de un hecho delictivo, véase, lo comentado por Galán (2008: 279 y ss.).

35 A favor de esta restrictiva interpretación, se manifiesta, sin embargo, por ejemplo, Núnez (2013: 170).

${ }^{36}$ En este sentido, señala CAMPO (2015: 71), citando la STS no 481/2014 de 3 de junio, que, mientras la apología del art. 18 CP exige la invitación directa a cometer un delito concreto, el enaltecimiento o justificación del terrorismo del art. 578 CP "constituye una forma autónoma de apología caracterizada por su naturaleza genérica, sin integrar una provocación ni directa ni indirecta a la comisión de un delito concreto"; postura coincidente con la sostenida por Manjón (2004: 580) cuando señalaba que el comentado delito "tipifica un comportamiento apologético, que no requiere incitación directa ni indirecta, que no es un acto preparatorio, que no es provocación, que no se castiga por el peligro ni siquiera abstracto para un bien juridico siquiera de referencia de los delitos de terrorismo, que tiene naturaleza de delito autónomo (...) y que tiene una pena propia", en "Apología del terrorismo"; afirmando también Ramos
} 
Galán - Nuevas formas de terrorismo, nuevos instrumentos penales...

Sin embargo, pese a que esta controvertida opción interpretativa sigue abierta y parece haberse visto incluso respaldada por la aceptación por parte de nuestro Tribunal Constitucional de la existencia y constitucionalidad de los denominados "delitos de clima" en alguna no muy lejana sentencia referida a otras figuras de expresión ${ }^{37}$, no parece que ello haya satisfecho plenamente al legislador en su empeño por sancionar los actos de incitación terrorista generales e indirectos.

Así lo demuestra, a nuestro modo de ver, el hecho de que el delito de colaboración terrorista además de castigar la mera organización de prácticas de entrenamiento terrorista (art. 577.1 CP), la captación de futuros terroristas o su adiestramiento (art. 577.2 CP), haya pasado, tras la reforma realizada por la LO $2 / 2015$, también a sancionar tanto las conductas de adoctrinamiento que estén "dirigidas" a incitar a cometer cualquier delito terrorista, que ya castigaba la versión anterior de este delito, como las que "... por su contenido, resulte idónea para incitar a incorporarse a una organización o grupo terrorista, o para cometer cualquiera de los delitos comprendidos en este Capitulo", lo que, a nuestro entender, determinará que nos encontremos, ahora sí, ante una figura especialmente adecuada para poder llegar a sancionar los actos de incitación implícita o indirecta y meramente genérica a cometer delitos terroristas de los que hablaba la Decisión Marco anteriormente citada.

Así lo indica, a nuestro juicio, no solo el hecho de que el comentado precepto castigue tras la reforma los actos adoctrinadores que se dirijan o que simplemente resulten idóneos para incitar a efectuar "cualquier" delito terrorista y no "alguno" de ellos, como por ejemplo hacían las anteriormente comentadas

(2008: 784) que no se podría considerar que dicho delito requiera realmente de una provocación directa al delito tal y como exige el art. $18 \mathrm{CP}$, ya que ello contrariaría el propio tenor del comentado precepto así como la finalidad con la que se creó. En términos similares, se manifiesta Muñoz (2015: 789) quien precisamente entiende que, al no atenerse el comentado precepto, en su modalidad de enaltecimiento o justificación del terrorismo, a los límites del art. $18 \mathrm{CP}$, su existencia plantearía serias dudas de constitucionalidad.

${ }^{37}$ En concreto, se trata de la Sentencia del Tribunal Constitucional de 7 de noviembre de 2007, relativa a la constitucionalidad del delito de negacionismo y justificación del genocidio del, en aquel entonces vigente, art. $607 \mathrm{CP}$; sentencia en la que, si bien se declaró la inconstitucionalidad del castigo del negacionismo como tal, sí que se admitió la compatibilidad con la Carta magna de aquella parte del comentado delito que castigaba la justificación del delito de genocidio, precisamente porque la manifestación acorde o la valoración positiva de su realización presenta un elemento tendencial de creación de un clima social de hostilidad que podría incitar indirectamente a la comisión de tan odioso delito; delimitación que, por ejemplo, a juicio de RAMOS (2008: 788 y ss. Y 799 y ss.) podría transponerse al delito de enaltecimiento y justificación del terrorismo, convirtiéndolo en un delito de clima que indirectamente incitaría a cometer delitos de dicha naturaleza. Sobre el origen y desarrollo de esta corriente jurisprudencial que hunde sus raíces en la evolución de la jurisprudencia emanada del Tribunal Europeo de Derechos Humanos y, en concreto de la interpretación que dicho Tribunal ha realizado del art. 10 del CEDH en relación con el art. 17 de dicho convenio, para permitir la prohibición de los discursos de odio, véase, Rodríguez (2011: 221 y ss.). Sobre el origen dogmático de esta categoría de delitos y su posible aplicación a otros delitos de nuestro Código penal, como el contenido en el art. $510 \mathrm{CP}$, véase, lo comentado por Gómez (2012: 89 y ss.). 
conductas incitadoras indirectas o implícitas de delitos concretos castigadas en el ya comentado art. 579.1. CP, sino también y especialmente el que el delito de colaboración terrorista en general sea una figura que castiga el suministro, por parte de personas no integradas en una organización o grupo terrorista, ${ }^{38}$ de ayudas o contribuciones genéricas a cometer delitos de dicha naturaleza y no las ayudas puntuales que simplemente tiendan a facilitar la comisión de uno o varios de ellos en concreto. ${ }^{39}$

Este hecho convertiría al delito de colaboración terrorista en un delito de peligro abstracto completamente autónomo del resto de figuras de terrorismo, como lo demuestra el hecho de que castigue a quien cometa cualquiera de sus muy variopintas modalidades comisivas con una pena propia (de 5 a 10 años de prisión) completamente independiente de la establecida para la autoría o participación en el resto de dichos ilícitos. Un delito que al contemplar expresamente entre sus posibles modalidades comisivas a los actos adoctrinadores que implícita o indirectamente puedan incitar a cometer delitos terroristas en general, permitirá que el ordenamiento penal español pueda finalmente responder a las exigencias incriminadoras europeas de las nuevas formas de provocación terrorista, haciendo factible que pueda castigar la difusión o transmisión del discurso del odio que caracteriza y tan buenos resultados está dando al terrorismo yihadista y que, además de no contener siempre una incitación manifiesta o clara a cometer delitos, en muchas ocasiones ni siquiera se realiza de una forma que pueda considerarse como

\footnotetext{
${ }^{38}$ De hecho, Cancio (2011: 661) señalaba con relación a la anterior redacción de este precepto que el mismo parecía olvidar que, generalmente, las labores de adoctrinamiento y captación se suelen realizar por miembros de la organización y, por tanto, están ya perfectamente tipificadas y castigadas por los delitos de pertenencia a los mismos que tiene preferente aplicación, con lo que su expresa calificación como colaboración terroristas tiene escasa utilidad. De hecho, el referido autor (2010b: 1004) señalaba que la práctica judicial relativa al delito de pertenencia a organización terrorista había precisamente considerado como una de las actividades que permitían apreciar su realización la de "...convencer a otros para realizar la yihad, esto es, el adoctrinamiento en el fundamentalismo islámico”. En la misma línea, señalaba García (2011: 2260) que incluso “...en el improbable supuesto de que la organización decidiese "externalizar" sus servicios de captación adiestramiento y formación "tertium no datur", tanto si la prestación de tales servicios se encomienda a un grupo de personas como a una sola, entonces o el grupo resultaría ser en si mismo "organización o terrorista" (...) o bien la persona -el captador o adiestradorindividual habría de considerarla necesariamente como integrante, directamente de aquel grupo. Sólo queda entonces como hipótesis, una intervención puntual o episódica en tareas de captación, adiestramiento o formación”. El carácter completamente residual y excepcional de la aplicación de este precepto respecto a los actos de captación y adoctrinamiento frente a los delitos de integración en grupo u organización terrorista queda de manifiesto en las todavía escasas sentencias que han recaído sobre conductas de captación y adoctrinamiento de yihadista, como sería, por ejemplo, la Sentencia num. 789/2014 de 2 diciembre del Tribunal Supremo, referida a la condena del conocido como "Bibliotecario de $\mathrm{Al}$ Qaeda", o la todavía más reciente Sentencia, 23/2015, de 30 de septiembre, de la Audiencia Nacional que condenó a una célula de captación y reclutamiento de combatientes yihadistas en Ceuta, para la guerra que se viene desarrollando en Iraq y Siria.

${ }^{39}$ En este sentido, ya señalaba Núnez (2013: 145) en relación a la anterior redacción de este delito, que la colaboración propia del mismo "debe ser genérica, es decir no vinculada a una actividad concreta sino que conste en un apoyo genérico..." mientras que "...si este apoyo material se concreta en una determinada conducta delictiva, la colaboración cede ante la coautoría o la complicidad"; postura que también comparte, entre otros, García (2011: 2249).
} 
Galán - Nuevas formas de terrorismo, nuevos instrumentos penales...

dirigida ni idónea, desde un punto de vista ex ante, para incitar a la comisión de delitos terroristas concretos y determinados, sino para fomentar la genérica e indeterminada realización de cualquiera de ellos en el futuro.

Ahora bien no todo son luces en este precepto. De hecho, los problemas y cuestiones que su amplia redacción viene a plantear proyectan una larga y oscura sombra de duda sobre la posible la legitimidad de su existencia.

Así por ejemplo y en primer lugar, parece evidente que el hecho de que esta figura convierta en autor de un delito completamente autónomo del resto de los terroristas a quien sería, todo lo más un mero favorecedor o incitador ideológico genérico de los ilícitos que otro podría llegar a cometer en el futuro como consecuencia de su actuación, abre las puertas de par en par a que se pueda llegar a plantear si cabría considerar a su vez, como inductor o incluso como provocador del delito de colaboración terrorista a quien induzca o simplemente intente inducir públicamente a un tercero para que adoctrine a otros incitándoles a cometer delitos de terrorismo en general; ${ }^{40}$ posibilidad que, a nuestro juicio, hay que negar de forma tajante, ya que supondría admitir la existencia y la relevancia penal en esta materia de una modalidad ciertamente particular de "inducción en cadena", incluso meramente intentada, figura esta que ha sido tradicionalmente rechazada por la doctrina, ${ }^{41}$ incluso en su forma consumada, precisamente y entre otras cosas por considerar, acertadamente a nuestro modo de ver, que su admisión supondría un adelantamiento excesivo e inadmisible de las barreras de intervención penal. ${ }^{42}$

Por otra parte, resulta llamativo que el artículo del Código Penal español que venimos comentado castigue el "adoctrinamiento" y no la mera difusión pública de ideas o contenidos objetivamente peligrosos a los que aludía precisamente la propia Decisión Marco 2002/475/JAI en la que parecía tener origen, ${ }^{43}$ algo que, a nuestro modo de ver, no es en modo alguno consecuencia de una elección puramente casual del legislador español, sino de una muy meditada decisión por su parte, ya que dicha expresión, si bien mantiene al margen de este tipo delictivo, por ejemplo a todas aquellas actuaciones que podría realizar aquel periodista o cómico que difunda o comunique mensajes o viñetas que se mofen de las ideas y símbolos que defienden los seguidores de los radicales terroristas, por más que estos puedan resultar

\footnotetext{
${ }^{40}$ Este posible y cuestionable efecto ampliador, que permitiría castigar el mero acto preparatorio de lo que, todo lo más, sería a su vez, otro acto preparatorio ya fue puesto de manifiesto por Campo (2015: 75).

${ }^{41}$ Mir (2015: 419), Muñoz/García (2015: 473), Olmedo (2000: 308), entre otros

42 A este respecto véase lo comentado, por ejemplo, por Gómez (1995: 123 y ss. y 127).

43 Así lo destacó en su día, Cancio (2011: 662 y 663) quien además señalaba que ello contrastaba claramente con el hecho de que la citada Decisión Marco afirmase expresamente en su considerando 14 que "la expresión pública de opiniones radicales, polémicas o controvertidas sobre cuestiones politicas sensibles, incluido el terrorismo, queda fuera del ámbito de la presente Decisión Marco y, en especial, de la definición de provocación a la comisión de delitos de terrorismo", lo que le llevaba a cuestionarse el posible encaje de esta modalidad con el propio Estado de Derecho. En idénticos términos se manifiesta también Núnez (2013: 238).
} 
absolutamente idóneos desde un punto de vista ex ante para determinar a alguno de sus destinatarios a cometer algún delito terrorista todavía por determinar y se pueda efectuar incluso sabiendo que pueden llegar a provocarlos, sí que permitirá castigar la instrucción, transmisión o enseñanza de ideas, creencias u opiniones que se correspondan con los postulados defendidos por los terroristas y se transmitan conociendo su peligrosidad incitadora. Esto es, la de las doctrinas que defienden y sustentan los diferentes movimientos terroristas. ${ }^{44}$

Podría pensarse entonces que dicha decisión del legislador patrio es acertada y positiva, ya que restringe significativamente el ámbito típico de esta concreta modalidad comisiva del delito de colaboración terrorista, limitándolo precisamente a los peligrosos discursos que utilizan los terroristas para captar apoyos. Sin embargo la pregunta surge de forma inmediata. Si este ilícito solo permite castigar la transmisión de ideas defendidas desde el terrorismo (las adoctrinadoras) y no de las que pueden de forma general llevar a generar delitos de terrorismo, ¿no estaremos dejando de perseguir la transmisión de ideas por la peligrosidad lesiva que presentan para los bienes protegidos por los tradicionales delitos de terrorismo para pasar a castigar directamente el simple mantenimiento o transmisión de los postulados defendidos por los terroristas?, ¿No supone ello negar la posibilidad de defender dichas ideas y postulados y, por tanto, tratar imponer un pensamiento único sobre los temas que se cuestionan desde los movimientos terroristas, acabando de esa forma con la libertad de opinión, expresión e información sobre los mismos? ${ }^{45}$

Frente a esto se podría señalar que, en realidad el precepto ahora analizado no castiga simplemente la enseñanza o transmisión de ideas, postulados o doctrinas sostenidos por los terroristas por muy radicales que puedan ser, salvo si los mismos se dirigen o resultan idóneos, en el caso concreto, para poder incitar a cometer delitos terroristas a sus destinatarios, ${ }^{46}$ lo que permitiría defender y transmitir

\footnotetext{
${ }^{44}$ Resulta significativo en tal sentido que mientras la conducta de adoctrinar aparecer definida en el Diccionario de la Real academia de la Lengua española como la conducta consistente en "Inculcar a alguien determinadas ideas o creencias", precisamente defina el vocablo doctrina en su tercera acepción como el "Conjunto de ideas u opiniones religiosas, filosóficas, politicas, etc., sustentadas por una persona o grupo", lo que sin duda, delimitará la posible aplicación de esta modalidad comisiva a las conductas de transmisión de ideas religiosas, políticas y filosóficas que se incluyen en el ideario general de los grupos u organizaciones terroristas (a las doctrinas) y no a las que, por muy peligrosas que pudiesen ser, se sustenten de forma puntual por un sujeto sin estar encuadradas dentro de un ideario previamente configurado.

45 En este sentido, hay que recordar que, como señalaba Vives (2006: 41) resultaría del todo incongruente con la afirmación de la existencia de la libertad ideológica y de expresión de los Estados democráticos que fuesen precisamente dichos Estados los que decidiesen por los ciudadanos, supuestamente libres y autónomos, qué clase de ideas podrían llegar a conocer y cuáles no, ya que al hacerlo se les estaría negando la racionalidad, autonomía y libertad que supuestamente el ordenamiento les reconoce.

${ }^{46}$ En tal sentido, señalaba, por ejemplo, en relación a la anterior versión de este precepto, García (2011: 2261) que el hecho de que el castigo de la conducta de adoctrinamiento pudiese plantear problemas por poder suponer la punición de la simple opinión manifestada, lo que trataba precisamente de evitar la ya citada Decisión Marco 2002/475/JAI, fue lo que llevó al legislador
} 
Galán - Nuevas formas de terrorismo, nuevos instrumentos penales...

libremente dichos postulados en el resto de supuestos y además dotaría de antijuridicidad material a los actos comunicativos o instructores verdaderamente típicos del delito ahora analizado. Sin embargo y a nuestro modo de ver, esta posible interpretación se enfrentaría a un claro y grave problema, ya que, al castigar el vigente art. 577.2 CP como delito autónomo y consumado la mera realización de conductas de adoctrinamiento, esto es de mera transmisión de determinadas ideas o doctrinas que ni tienen que contener una manifiesta y expresa incitación a cometer delitos terroristas en general (puede ser tácita o implícita), ni tienen que resultar adecuadas desde un punto de vista ex ante para incitar a sus posibles receptores a cometer uno o varios delitos concretos y previsibles de dicha naturaleza (pueden incitar a cometerlos de forma genérica), se desdibujan hasta tal punto los referentes conforme a los que se debería valorar la idoneidad incitadora que las ideas o informaciones "adoctrinadoras" tendrán que tener para ser típicas de esta figura, que se hace realmente difícil de determinar cuáles de entre ellas tendrán encaje en la misma y cuáles se mantendrán al margen de su tipicidad.

Así por ejemplo ¿criticar la política que estuviese llevando un determinado país con respecto al colectivo musulmán ante un sujeto que se supiese o se sospechase que era afín o proclive a defender las ideas y métodos empleados por el terrorismo yihadista contrario a dicha política, podría llegar a ser considerado como un acto de adoctrinamiento castigado por el delito ahora analizado, al poder entenderse que quien la realizó efectúo una actuación adoctrinadora que sabía que podría objetivamente llevar a su destinatario a cometer algún acto terrorista, por más que no supiese ni se hubiese planteado siquiera cuál en concreto podría este llegar a ser?, ¿Afirmar en un debate televisado que el tratamiento que estaban recibiendo los musulmanes en un determinado conflicto bélico era injusto y delictivo internacionalmente, como había previamente afirmado un determinado grupo u organización terrorista que llamaba además a la "guerra santa contra los infieles" como represalia, trasmitiría una idea adoctrinadora adecuada o idónea para que alguno de los posibles e indeterminados receptores de tal mensaje pudiese decidirse a incorporarse a dicha guerra cometiendo una agresión terrorista cualquiera o integrándose o colaborando con dicha organización?

La amplitud e indeterminación de la nueva regulación parece ciertamente muy difícil de aceptar por un Estado de Derecho respetuoso con los derechos y libertades fundamentales de la persona, que realmente se quiera tener por tal.

Pero es que además si a esto se le añade que, tras la reforma efectuada por la LO 2/2015, el delito de colaboración terrorista no solo castigará los actos adoctrinadores que se cometan con dolo de incitar a la realización de ilícitos de dicha naturaleza por parte de terceros o teniendo, cuando menos, conciencia de

patrio optase acertadamente por vincular la posible relevancia penal de los mensajes que contemplaba este delito con la posible incorporación de otros a organizaciones terroristas o a la realización de delitos de dicha naturaleza, provocando, sin embargo, el solapamiento de esta figura con las de proposición, provocación o, incluso con la inducción. 
que las ideas transmitidas podían previsiblemente llegar a producir tal resultado (con un dolo de peligro), sino también y atendiendo a lo establecido en el nuevo apartado 3 del art. $577 \mathrm{CP}$, los que transmitan o enseñen dichas peligrosas ideas simplemente con imprudencia grave -lo que, como es sabido, si bien obliga a tener que constatar que se había difundido o comunicado con infracción del deber de cuidado exigible a aquel que lo transmitió, no requerirá que la haya realizado siendo siquiera consciente de su peligrosidad-, el panorama normativo que se nos presenta resulta ya del todo desolador.

No solo nos encontramos ante un delito que no da unos referentes claros a la hora de determinar las ideas o doctrinas cuya enseñanza o transmisión quiere castigar. Además estamos ante uno que transmite directa y expresamente a los ciudadanos el mensaje de que por más que no se representen ni siquiera como posible que la idea o postulado acorde con los defendidos por los terroristas que quieran transmitir o enseñar pueda resultar idóneo o adecuado, en el caso concreto, para llevar a alguno de sus destinatarios a decidirse a cometer algún delito de terrorismo, dicho hecho no tendrá por que suponer que se mantengan exentos de responsabilidad penal por haberlos exteriorizado, trasmitido o enseñado. Un mensaje sin duda, que llevará a que más de uno de dichos ciudadanos se abstenga de defender o expresar tales ideas y doctrinas ante terceros por más que estuviesen perfectamente amparadas por los derechos fundamentales, a las libertades de expresión y de información en el caso y de la forma que pretendían hacerlo ante el temor de que su posible equivocación a la hora de valorar su peligrosidad pudiese llegar a ser, precisamente, la que fundamentase su responsabilidad penal por imprudencia, generándose así un evidente efecto de desaliento sobre el posible ejercicio legítimo de tales libertades fundamentales por parte de tales personas; efecto que resulta a todas luces desproporcionado y obliga, en consecuencia, a considerar que la existencia de este delito es incompatible con el reconocimiento y protección que nuestra constitución otorga a las citadas libertades fundamentales, convirtiéndolo así en manifiestamente inconstitucional. ${ }^{47}$

\section{5. ¿Una represión penal de ideas que matan personas mediante leyes que matan ideas?}

A lo largo de este trabajo hemos visto cómo el legislador español ha utilizado de nuevo al terrorista y al temor que genera en la sociedad en su conjunto, para volver a reformar la ya de por sí excepcionalmente amplia y represiva legislación penal destinada a luchar contra tal fenómeno criminal, procediendo a dar la enésima ( $\mathrm{y}$

\footnotetext{
${ }^{47}$ En este sentido, señalaba, por ejemplo, Prieto (2003: 296) que, aunque haya un ejercicio ilícito de la libertad de expresión "una reacción penal excesiva frente a este ejercicio ilicito puede producir efectos disuasorios de desaliento sobre el ejercicio legitimo de los referidos derechos, ya que sus titulares, sobretodo si los limites penales están imprecisamente establecidos, pueden no ejercerlos libremente ante el temor de que cualquier extralimitación sea severamente sancionada"; efecto este que determinará que la medida penal que lo provoque, como sucede con la ahora comentada, tenga que ser considerada como desproporcionada y resulte, por tanto, inconstitucional.
} 
Galán - Nuevas formas de terrorismo, nuevos instrumentos penales...

no parece que última) vuelta de tuerca en la espiral intensificadora y ampliadora de la intervención penal que ha caracterizado a su política criminal frente a dicha forma de delincuencia.

Lo ha hecho, como suele tenernos ya acostumbrados, amparándose en supuestas y en la mayor parte de los casos realmente inexistentes exigencias supranacionales. Pero además, también lo ha hecho sin meditar de forma adecuada los problemas de todo tipo que una reforma del calado de la realizada va a plantear.

Todo ello ha llevado a que el panorama normativo establecido con respecto al terrorismo tras dicha reforma resulte aterrador. Delitos dotados de una amplitud típica tal que difícilmente pueden considerarse acordes con los principios penales básicos y las exigencias mínimas de seguridad jurídica y de taxatividad propios de un Estado de Derecho. Penas desproporcionadas a la gravedad de los hechos que castigan. Tipos delictivos redundantes que se solapan entre sí y que darán lugar a graves y arduamente resolubles problemas concursales. Figuras que se han creado de forma descoordinada con las que existían antes y cuya acumulada aplicación llevará a que se pueda plantear el castigo de actuaciones tan alejadas de una verdadera puesta en peligro de bienes jurídicos que carecen prácticamente de lesividad objetiva alguna. $\mathrm{Y}$ en fin, figuras que en su empeño, según se nos dice, por perseguir y prevenir al fenómeno terrorista en sus momentos más iniciales, restringen derechos y libertades fundamentales de los ciudadanos de forma tan desmedida y amplia que resulta imposible interpretarlas de forma acorde a nuestra constitución. ${ }^{48}$

Todo ello lleva a que resulte urgente realizar una nueva y completa revisión del régimen normativo establecido con respecto al terrorismo. Una revisión que no solo tendrá que solventar los evidentes y gravísimos problemas técnicos de toda índole que la legislación ya vigente viene a plantear, sino que también habrá de evitar que el Derecho Penal, en su supuesto empeño por prevenir y sancionar al terrorismo en sus manifestaciones más iniciales, más que perseguir a las ideas que los criminales utilizan para conseguir que se mate a personas, termine "matando" aquellas ideas que, por más que nos molesten o lo hagan a quien ostenta en cada concreto momento el poder de usar dicho instrumento represivo, tienen que ser expresadas con total libertad, si queremos impedir que sea el Derecho de los Estados supuestamente democráticos y no el terrorismo, el que finalmente termine por eliminar las libertades y derechos que hacen precisamente que dichos Estados se presenten como los espacios de convivencia pacífica y diálogo abierto entre diferentes culturas, creencias e ideologías, con los que justamente los nuevos terroristas, en su visión maniquea del mundo, tratan de acabar.

\footnotetext{
${ }^{48}$ No le falta razón, por tanto, a Cuerda (2008: 61 y ss.) cuando señala que las tres áreas o libertades políticas afectadas por el discurso de la emergencia propio del terrorismo, son la libertad de asociación, la ideológica, religiosa y de culto y, como no, la libertad de expresión.
} 


\section{BIBLIOGRAFÍA}

* Asúa Batarita, Adela (2002): "Concepto jurídico de terrorismo y elementos subjetivos de finalidad, Fines políticos últimos y fines de terror instrumental”, en Estudios jurídicos en memoria de José María Lindón, Ed. Universidad de Deusto, Bilbao.

* Aixala, Albert (2015): "La estrategia de la UE ante el terrorismo internacional y la defensa de los derechos y libertades", disponible en http://www.recercat.cat/bitstream/handle/2072/204360/6\%

20cap $\% 204$.pdf? sequence $=6$. (últ. vis., 10-12-2015)

* Barber Burrusco, María Soledad (2004): Los actos preparatorios del delito. Ed. Comares, Granada.

* Barquín Sanz, Jesús (2015): "De las formas sustitutivas de la pena de prisión y de la libertad condicional", en Estudios sobre el Código penal reformado (Leyes Orgánicas 1/2015 y 2/2015) Ed. Dykinson, Madrid.

* Bernal del Castillo, Jesús (2011): "Una visión crítica del nuevo delito de provocación al terrorismo del art. 579.1”, en RDP nº 33.

* Campo Moreno, Juan Carlos (2000): Los actos preparatorios punibles. Ed. Tirant lo Blanch., Valencia.

(2015): Comentarios a la reforma del Código penal en materia de terrorismo: L.O. 2/2015, Ed. Tirant lo Blanch, Valencia.

* CANCiO Meliá, Manuel (2000): "Strafrecht und Terrorismus in Spanien. Anmerkung zur Entwicklung der Terrorismus gesetzgebung nach Diktatur" en Tranformation von Diktaturen in Demokratien und aufarbeitung der vergangenheit, . V. De Gruyter, Berlín/New York.

(2008): “Terrorismo y Derecho penal: Sueño de la prevención, pesadilla del Estado de Derecho", en Politica Criminal en vanguardia. Inmigración clandestina, terrorismo, criminalidad organizada. Ed. Thomson-Civitas, Cizur Menor (Navarra).

(2010a): Los delitos de terrorismo: Estructura tipica e injusto. Ed. Reus, Madrid.

(2010b): "El delito de pertenencia a una organización terrorista en el Código penal español”, en Derecho penal del Estado social y democrático de Derecho. Ed. La Ley, Madrid.

(2011): "Delitos de organización: Criminalidad organizada común y delitos de terrorismo" en Estudios sobre las reformas del Código penal operadas por las LO 5/2010, de 22 de junio, y 3/2011, de 28 de enero". Civitas, Cizur Menor (Navarra).

* Cano Paños, Miguel Ángel (2015a): "La reforma penal de los delitos de terrorismo en el año 2015. Cinco cuestiones fundamentales", RGDP 23, disponible en http://www.iustel.com (últ. vis. 13-11-2015).

(2015b): "La reforma de los delitos de terrorismo", en Estudios sobre el Código Penal reformado (Leyes Orgánicas 1/2015 y 2/2015) Ed. Dykinson, Madrid.

(2009): "Reflexiones en torno al "viejo" y al "nuevo" terrorismo", en REIC 7, p. 2 y ss., disponible en http://www.criminologia.net/pdf/reic/ano72009/a72009art7.pdf (últ. vis. 13-11- 2015)

* CORTÉs Bechiarelli, Emilio (2015): Nociones fundamentales de Derecho penal. Parte Especial. Vol. II Ed. Tecnos, Madrid.

* Cuerda Arnau, María Luisa (2008): “Terrorismo y libertades políticas" en Teoría y Derecho, junio $3 / 2008$.

* Fernández Ogallar, Beatriz (2014): El Derecho penal armonizado de la Unión Europea, Ed. Dykinson, Madrid.

* Fuente Cobo, Ignacio (2015): "El yihadismo en su contexto histórico", en Cuadernos de estrategia, 173. Ed. Ministerio de Defensa, Madrid, disponible en http://www.ieee.es/Galerias/fichero/ cuadernos/CE 173.pdf (últ vis. 10-12-2015)

* Galán Muñoz, Alfonso (2008): "El Denominado "Dolo Alternativo": Un caso entre el concurso de leyes y el de Delitos", en Problemas actuales del Derecho penal y la criminología. Estudios penales en memoria de la Profesora Dra. Maria del Mar Díaz Pita. Ed. Tirant lo Blanch, Valencia. 
Galán - Nuevas formas de terrorismo, nuevos instrumentos penales...

(2014): “La protección de datos de carácter personal en los tratamientos destinados a la prevención, investigación y represión de delitos: hacia una nueva orientación de la política criminal de la Unión Europea”, en La Ley 4619/2014.

* García Albero, Ramón (2011): Comentarios a la Parte Especial del Derecho penal. Aranzadi, Cizur Menor (Navarra).

* García Pérez, Octavio (1993): "Delitos de sospecha: Principio de culpabilidad y derecho a la presunción de inocencia. Los art. 483 y 485 CP”, ADPCP, T. 46.

* Gómez Martín, Víctor (2010): “Notas para un concepto funcional de terrorismo”, en Terrorismo y Estado de Derecho, Iustel.

(2012): "Discurso del odio y principio del hecho", en Protección penal de la libertad de expresión e información. Una interpretación constitucional. Ed. Tirant lo Blanch, Valencia.

* Gómez Rivero, María del Carmen (1995): La inducción a cometer el delito. Ed. Tirant lo Blanch, Valencia.

* González Cussac, José Luis (2006): "El Derecho penal frente al terrorismo. Cuestiones y perspectivas", en Terrorismo y proceso penal acusatorio, Ed. Tirant lo Blanch, Valencia. (2007): "Nuevas amenazas a la seguridad nacional: los desafíos del nuevo terrorismo", en Retos de la politica criminal actual. Revista Galega de Seguridad Pública, 9.

* Jakobs, Gunther (2006): Derecho penal del enemigo. Ed. Civitas, Madrid.

* Larriba Hinojar, Beatriz (2009): "Globalización, terrorismo y libertad de expresión: Conminación penal de actividad terrorista en el entorno virtual”, en Constitución, derechos fundamentales y sistema penal. T. II. Ed. Tirant lo Blanch, Valencia.

* López Peregrín, Carmen (2003): “¿Lucha contra la criminalidad mediante el cumplimiento íntegro y efectivo de las penas?", REIC 1 disponible en http://www.criminologia.net/pdf/reic/ano1-2003/a12003art2.pdf (últ. vis. 2-11-2015).

* Manjón CaBeZa, Aracely (2004): "Apología del terrorismo”, en Estudios penales en recuerdo del profesor Ruiz. Antón, Ed. Tirant lo Blanch, Valencia.

* Mir Puig, Santiago (2002): Derecho penal. Parte General. Ed. Reppertor, Barcelona. (2015): Derecho penal. Parte Especial. Ed. Reppertor, Barcelona.

* Muñoz Conde, Francisco (2010): Derecho penal Parte General. Ed. Tirant lo Blanch, Valencia. (2015a) Derecho penal Parte Especial. Ed. Tirant lo Blanch, Valencia.

* Muñoz Conde, Francisco/ García Arán, Mercedes (2015b): Derecho penal. Parte General. Ed. Tirant lo Blanch, Valencia.

* NúÑez Castaño, Elena (2013): Los delitos de colaboración con organizaciones y grupos terroristas. Ed. Tirant lo Blanch, Valencia.

* Olmedo Cardenete, Miguel (2000): Comentarios al Código penal, Tomo III, Ed. Edersa, Madrid.

* Prieto Sanchís, Luis (2003): “La limitación constitucional al legislador penal”, en Justicia constitucional y Derechos fundamentales, Ed. Trotta, Madrid.

* Ramos Vázquez, José Antonio (2008): "Presente y futuro del delito de enaltecimiento y justificación del terrorismo", en AFCUC, 12.

* Rebollo Vargas, Rafael (1997): La provocación y la apología en el nuevo Código penal. Ed. Tirant lo Blanch, Valencia.

* Rodríguez Montañés, Teresa (2011): Libertad de expresión, discurso extremo y Delito. Una aproximación desde la constitución a las fronteras del derecho penal. Ed. Tirant lo Blanch, Valencia.

* SÁnchez García de Paz, Isabel (2008): "Problemas de legitimidad de una respuesta excepcional frente a las organizaciones criminales", en Política Criminal en vanguardia. Inmigración clandestina, terrorismo, criminalidad organizada. Ed. Thomson-Civitas, Cizur Menor (Navarra), 2008.

* VIVES Antón, Tomás Salvador (2006): "Sistema democrático y concepciones del bien jurídico; el problema de la apología del terrorismo", en Terrorismo y proceso penal acusatorio, Ed. Tirant lo Blanch, Valencia.

* ZúNiga Rodríguez, Laura (2009): Criminalidad organizada y sistema de Derecho penal. Contribución a la determinación del injusto penal de organización criminal. Ed. Comares, Granada. 